\title{
Psychological Cognitive Factors Affecting Visual Behavior and Satisfaction Preference for Forest Recreation Space
}

\author{
Zhi Zhang, Yu Gao, Sitong Zhou, Tong Zhang *, Weikang Zhang and Huan Meng
}

Citation: Zhang, Z.; Gao, Y.; Zhou, S.; Zhang, T.; Zhang, W.; Meng, $\mathrm{H}$. Psychological Cognitive Factors Affecting Visual Behavior and Satisfaction Preference for Forest Recreation Space. Forests 2022, 13, 136. https://doi.org/10.3390/f13020136

Academic Editors: Hongxu Wei and Richard Hauer

Received: 8 December 2021

Accepted: 12 January 2022

Published: 18 January 2022

Publisher's Note: MDPI stays neutral with regard to jurisdictional claims in published maps and institutional affiliations.

Copyright: (C) 2022 by the authors. Licensee MDPI, Basel, Switzerland. This article is an open access article distributed under the terms and conditions of the Creative Commons Attribution (CC BY) license (https:// creativecommons.org/licenses/by/ $4.0 /)$.
Landscape Planning Laboratory, Forestry College, Shenyang Agricultural University, Shenyang 110866, China; zhangzhi@syau.edu.cn (Z.Z.); gaoy0121@126.com (Y.G.); 2019250199@stu.syau.edu.cn (S.Z.); zhwk1986@syau.edu.cn (W.Z.); 2016500016@syau.edu.cn (H.M.)

* Correspondence: tongzhang@syau.edu.cn

Abstract: Background: People are paying increasing attention to urban forest landscapes, and recreational landscape spaces (providing recreation and viewing functions) are an important part of the urban forest landscape. Visual tracking technology is a flexible and accurate modern research method. When this technology is applied to forest landscape evaluation, it can assist in explaining the content that could not be studied in depth in the past and has high application value. However, although an eye tracker can tell us what the user is looking at, it cannot tell us why they are looking at it or how they feel after seeing it. To this end, we combined a 7-point spatial cognition questionnaire and satisfaction preference to understand the visual behavior (fixation point time, number of fixation points, etc.) and preference satisfactions of users in recreational landscape spaces to help designers understand what elements attract people's visual attention and improve the design of these spaces. Methods: We used eye-tracking and cognitive questionnaires to obtain experimental data and used factor analysis and linear regression analysis of SPPS 23.0 to analyze data. Main purpose: Clarify the factors affecting people's visual behavior and satisfaction preferences in forest recreation spaces to provide theoretical guidance for planning and designing forest landscapes. Main results: (1) Places with more frequent eye movements have relatively lower satisfaction preferences; (2) The spatial perception factors affect participants' visual behavior, and satisfaction preference is different based on many indicators (WCB, WSO, WSN, SSH, etc.) in forest recreation space; (3) The professional background education affects the participants' visual-behavior evaluation of the recreational landscape space and also affects the participants' focus on the landscape preference. When the spatial type of forest recreation space changes, the spatial perception factors that affect the participants' visual behavior and satisfaction preferences also change. Based on the above, we suggest that in forest recreation space, the spatial perception indicators should be improved according to the characteristics of space itself, then improve the satisfaction preferences for the scene in a targeted manner to make participants produce effective and positive visual behavior. Meanwhile, for a well-built forest park, we should provide the landscape node with the best visual effect and satisfaction preference for tourists from different professional backgrounds on the park's tour route map based on the characteristics of the forest recreational landscape space.

Keywords: landscape architecture; urban forestry; forest landscape; forest recreation; evaluation value of visual behavior

\section{Introduction}

Forest recreational space is one of the important components of the urban forest system [1]. As landscape recreational resources, these spaces have multiple functions for urban residents, including recreation, walking, natural learning, health care and other functions [2,3]. On the other hand, forest recreational landscape spaces are the carriers and platforms of these functions. High-quality recreational spaces (spaces with high viewing value and highly attractive recreation) attract people to walk out of buildings and walk into 
nature, and encourage people to engage in various recreational activities that can help them eliminate negative emotions, such as fear or anxiety [4]. Therefore, how to provide users with a high-quality forest recreational landscape space to meet their needs is an important issue for forest resource managers and landscape architects.

\subsection{The Beauty and Rehabilitation Effect of the Landscape in Urban Forestry}

Previous studies have mainly used questionnaires or SBE (scenic beauty estimation) to analyze the relationship between the utilization status of urban forests, the user's subjective preference, and the aesthetic function of forest landscape from the perspective of utilization status and landscape aesthetics [5-7]. An increasing number of researchers are attempting to understand the impacts of different types of natural environments on people's mental health. The main components of mental health are positive and negative effects [8], while satisfaction preferences are the subjective factors of long-term cognitive health [9].

However, in addition to the aesthetic function of forests, the experience of forest "bathing" can also relieve fatigue and arouse positive emotions in users [2,3]. For example, experiencing the forest environment can promote positive emotions in middle-aged women and bring more mental health benefits to middle-aged and elderly people with chronic diseases [10]. Janeczko analyzed the effects of walking in apartments, green suburbs and two forests (coniferous forest and deciduous trees) on the mental and physical relaxation of young people. The results showed that whether it is walking in an urban environment with green plants or walking in a forest environment, both have a positive effect on the subjects' physical and psychological relaxation [11]. In terms of physiology, the forest experience can also promote people's brain relaxation [12-14], and lead to decreased heart rate, pulse and cortisol concentration [15].

In addition, a study by Chiang et al. showed that individuals' positive emotions inside the forest were significantly higher than those outside or periphery, while their negative emotions outside the forest increased [16]. Van den Berg et al. also observed that after exposure to urban streets and parks, there were significant differences in the pair-wise recovery of negative emotions [17], while Gatesleben and Andrews reported that for people who walked past environments characterized by high expectations and low refuge, their positive emotions increased significantly compared to low expectations and high refuge [18].

After participating in the 15-min winter forest bathing activity, the participants' negative emotion indicators "Tension-anxiety" and "Anger-hostility" were significantly reduced. At the same time, compared with the built environment, being in a snow-covered forest environment can maintain the subjective vitality level of people [19].

Further research by Janeczko et al., showed that environmental diversity helps to improve mood and has greater recovery. At the same time, natural protection forests will have a better relaxation effect on people in terms of emotional state, subjective vitality and restoration than artificially managed forests [20].

These studies suggest that recovery of mental health is associated with a variety of visual perceptions of different natural environments [21].

\subsection{Application of Eye Movement Technology in Forest Landscapes}

It is undeniable that at present, most of the relevant research is overly dependent on questionnaires, which will lead to an overestimation of the effect of urban forest experiences on psychological cognition [2]. Therefore, it is necessary to adopt a more accurate method to assist in measuring and recording people's cognitive processes when experiencing a landscape space.

Eye-tracking technology is a method of quickly and accurately tracking a participant's eyes using a series of eye-trackers and recording the participant's eye movement trajectory [22-24]. As early as the 19th century, some people used eye-tracking technology to obtain data about human eye movements to study the relationship between the visual behavior characteristics of users and their psychological cognition when looking at an 
object [25-27]. In the 1990s, this technology was first cited by European scholars in the study of forest landscapes [28].

At present, visual tracking technology is mainly developed around two levels of landscape differences and subject groups, combined with a forest resource beauty survey and other content to obtain interactive results. These results can be linked to other physical and psychological monitoring results to obtain an overall evaluation of forest landscape resources and public perception [29]. The research mainly adopts two visual stimulus modes: pictures of landscapes and landscapes in the field. Both of these methods can objectively measure the way people observe the landscape [25]. Additionally, compared with on-site surveys, survey methods that use landscape pictures for analysis have the advantages of convenient operation and strong experimental control. Additionally, the research result with pictures has no significant difference from the on-site landscape, so it is widely adopted by many scholars [30].

Research by Dupont et al., from different landscape types and their characteristics, evaluated the impact of landscape space types on users' visual behavior [31] and found that structures in the forest would interfere with human vision and that the degree of openness and heterogeneity of the landscape and the degree of panorama all affect the user's visual behavior [25,32-35]. Gao et al., pointed out that in the landscape space, the participants' visual behaviors tended to be concentrated at the lower center of the scene, on iconic buildings in the scene or on "interesting" landscape elements [32,33].

\subsection{Professional Education Background and Forest Landscape Assessment}

In addition, when it comes to visually assessing landscapes, users of different professional backgrounds often have opposite views [36,37]. Among them, the analysis results of the differences in the interest of people with different professional backgrounds (forestry experts and ordinary citizens) in the forest landscape show that the experts' observation of the landscape is more integrated and in-depth than that of amateurs $[38,39]$. These may be related to the way people perceive the landscape environment. Studies have shown that the same recreational landscape may indeed cause different perceptions of different people [40]. This may be because not everyone observes the landscape in their own way, so different people may not necessarily see the same landscape. This is an interesting question in the study of visual landscape assessment based on landscape photos. Of course, it is necessary to consult groups of observers with different professional backgrounds in these studies. If these groups do observe the landscape in different ways, people with different professional backgrounds will be more likely to see different landscapes. Among them, people with professional backgrounds will explore the landscape space more extensively, while non-professional people will spend more time and attention on the individual elements of the landscape [39]. However, research on how landscape visualization is perceived by different groups is unexplored [41]. Therefore, an in-depth analysis of how users from different backgrounds observe the landscape (or pictures) will help to better understand how their differences in landscape vision arise [39].

According to the above findings, eye-tracking technology provides a flexible and accurate modern research method. When it is applied for forest landscape evaluation, it can assist in solving the content that could not be studied in depth in the past and provides high application value.

For landscape architects, in the process of planning and designing the layout of the recreational landscape space, it is not only necessary to grasp the participants' satisfaction preferences and visual behavior. Understanding the cognitive factors that affect people with different professional backgrounds and which spatial cognitive factors affect people's visual behavior and satisfaction preferences when they experience the recreational landscape space also plays a very important role [33].

To address this issue, our research, with the help of eye-tracking technology, studied the spatial perception factors that affect participant's visual behavior and satisfaction preferences in forest recreation landscape spaces. That is, factor analysis and multiple linear 
regression analysis were used to clarify the factors that affect people's visual behavior and satisfaction preference when appreciating the forest recreation landscape space, to determine whether professional background and the change of spatial type will affect the participants' visual behavior and satisfaction preference, and to offer theoretical guidance for the planning and design of landscape nodes in forest parks in the future.

In fact, the users of forest recreational spaces are numerous and complex, and these tourists inevitably gather in forest parks. Therefore, when planning forest landscape resources, landscape planners must balance the landscape needs and satisfaction preferences of different groups of people [42]. Combining forest landscape resources with user assessments, in-depth analysis of how people from different backgrounds observe the landscape (photos) will help designers better understand the understanding of the landscape by users with different backgrounds and then plan and design forest landscape resources in a more targeted manner.

\section{Materials and Methods}

\subsection{Study Area}

According to our previous investigation on the activities (lookout, water or plant appreciation, etc.) that tourists mainly engage in the relevant forest recreational landscape space and the characteristics of the forest recreational landscape space we have selected [7], we divide the forest landscape recreational space into three types of forest recreation landscape spaces: space of forest waterscape, lookout and in-forest landscape [43].

According to the movement state of the water in landscape space, we divide the forest waterscape space into two types: dynamic waterscape and static waterscape space [44].

Based on the types of plants in the upper layer of the landscape space, the space of in-forest landscape is divided into the space of broadleaved forest landscape, coniferous forest landscape and mixed forest landscape.

Then, through on-site investigation and screening, from the representativeness and universality of forest space, five forest parks in Liaoning Province of northern China were selected as the sample plots of our study, see Figure 1.

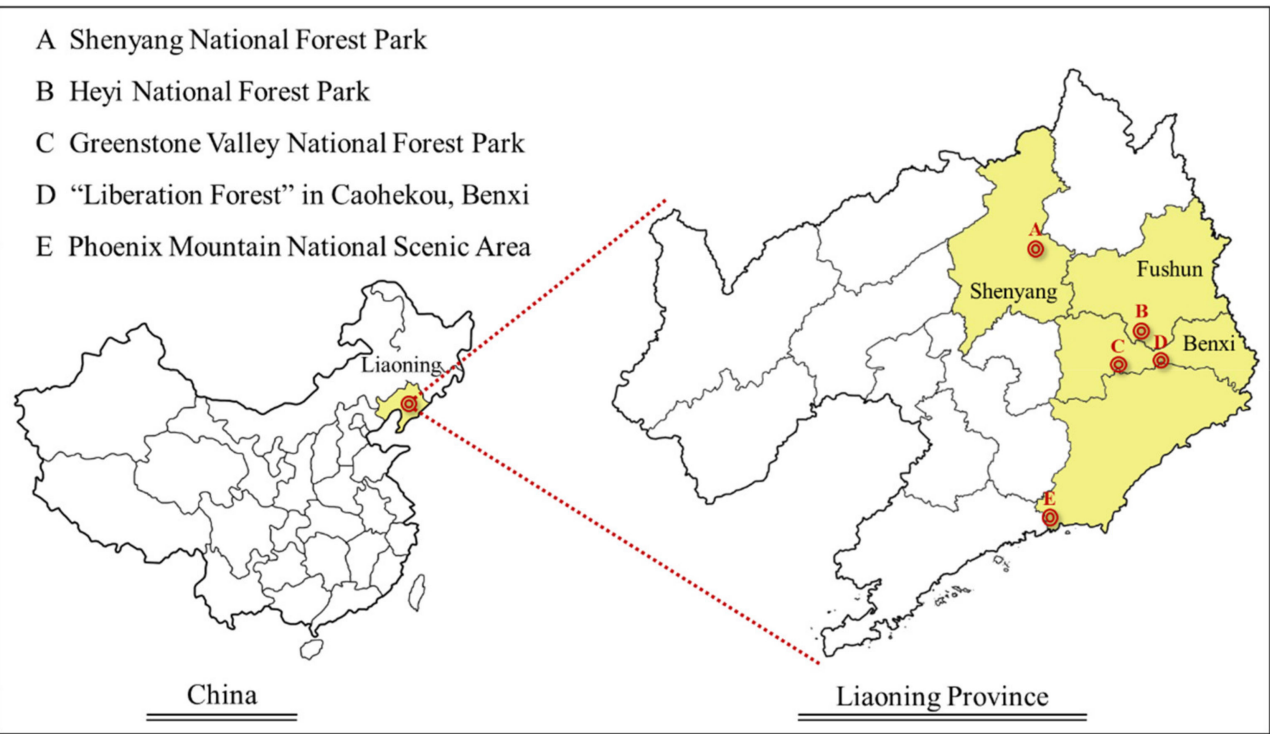

Figure 1. Locations of the study sites. This figure was created by Yu Gao (Shenyang Agricultural University).

A: Shenyang National Forest Park, with a longitude of $\mathrm{N} 42^{\circ} 01^{\prime} 30.18^{\prime \prime}$ and E $123^{\circ} 43^{\prime} 49.35^{\prime \prime}$, is a "national forest park". The black pine forest and the original secondary forest ecology in the park were about 9 square kilometers, and the forest coverage rate was up to $96 \%$. Originally belonging to Shenyang Forest Farm, it was approved by the State Forestry Administration in 1997. In this space, the average tree age is 
about 30 years, mainly composed of black pine (Pinus thunbergii Parl), Mongolian oak (Quercus mongolica Fisch. ex Ledeb), Cotinus coggygria (Cotinus coggygria Scop), goldenrain tree (Koelreuteria paniculata Laxm), mono maple (cer mono Maxim) and other colorful leaf tree species. The green vision rate in the space is about $96 \%$;

B: Heyi National Forest Park has a longitude of $\mathrm{N} 41^{\circ} 45^{\prime} 49.24^{\prime \prime}$ and E $124^{\circ} 42^{\prime} 10.53^{\prime \prime}$. Originally belonging to the Heyi Forest Farm Resort, it was approved by the State Forestry Administration to be built as a national forest park in 2008. The vegetation coverage rate in the park is high, and natural secondary forests and artificial forests are distributed. In this space, the average tree age is about 20 years, mainly composed of Mongolian oak (Quercus mongolica Fisch. ex Ledeb), goldenrain tree (Koelreuteria paniculata Laxm), mono maple (cer mono Maxim) and other colorful leaf tree species. The green vision rate in the space is about $92 \%$;

C: Greenstone Valley National Forest Park, with a longitude of N $41^{\circ} 04^{\prime} 31.28^{\prime \prime}$, E $124^{\circ} 11^{\prime} 45.93^{\prime \prime}$ and diverse undulating terrain and rich vegetation, is a typical mountain-type forest park. It belongs to the Forestry Bureau of Nanfen District, Benxi, and was approved by the State Forestry Administration in November 1991. In this space, the average tree age is about 25 years, mainly composed of Mongolian oak (Quercus mongolica Fisch. ex Ledeb), mono maple (cer mono Maxim) and other colorful leaf tree species. The green vision rate in the space is about $24 \%$;

D: "Liberation Forest" in Caohekou, Benxi, with a longitude of N $40^{\circ} 51^{\prime} 59.51^{\prime \prime}$ and E $123^{\circ} 54^{\prime} 03.70^{\prime \prime}$, is China's first artificially planted red pine forest. It originally belonged to the Liaoning Provincial Forest Management Research Institute, the Caohekou scientific research demonstration base. Because some areas are under open management, it provides a venue for local residents for leisure activities. In this space, the average tree age is about 70 years, mainly composed of Korean pine (Pinus koraiensis Sieb. et Zucc). The green vision rate in the space is about $60 \%$;

E: Phoenix Mountain National Scenic Area, with a longitude of N 40 $51^{\prime} 59.51^{\prime \prime}$ and E $123^{\circ} 54^{\prime} 03.70^{\prime \prime}$, has a rich dynamic water landscape space. In January 1994, Phoenix Mountain was approved by the State Council as one of China's key national scenic spots. In this space, the average tree age is about 20 years, mainly composed of Mongolian oak (Quercus mongolica Fisch. ex Ledeb), Cotinus coggygria (Cotinus coggygria Scop), mono maple (cer mono Maxim) and other colorful leaf tree species. The green vision rate in the space is about $56 \%$.

\subsection{Research Materials}

First, a study by Cottet et al., indicated that the results of photo-based eye tracking are consistent with those obtained in real scenes [31,39,45-47]. At the same time, in order to avoid some environmental factors (sound, temperature, humidity, etc.) affecting participants in the field experiment, in our experiment, we collected photos of the landscape space as experimental materials.

Second, in order to provide the consistency of vegetation, in our study all the pictures used were taken by Olympus EM5 SLR camera during the autumn maple season from 1 October to 3 October 2017 on a sunny day from 10:00 am to 11:00 am at a height of $170 \mathrm{~cm}$ and a distance of $10 \mathrm{~m}$ from the edge of the object space [31,47]. In the end, a total of 50 spatial sample pictures were collected, and 6 representative landscape pictures were selected by 10 landscape experts and 20 amateurs as our final materials to conduct related experiments. Each picture corresponds to a typical forest recreation landscape type (Figure 2). 


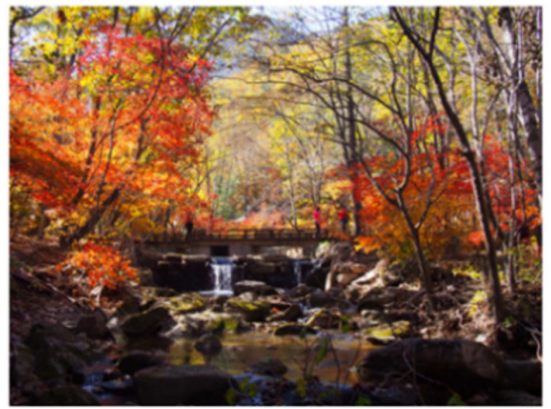

Space of dynamic water

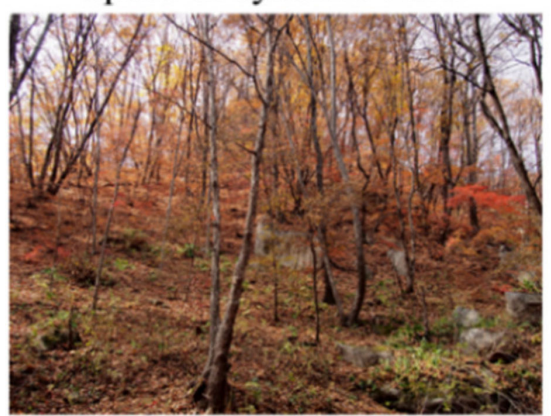

Space of broadleaf landscape
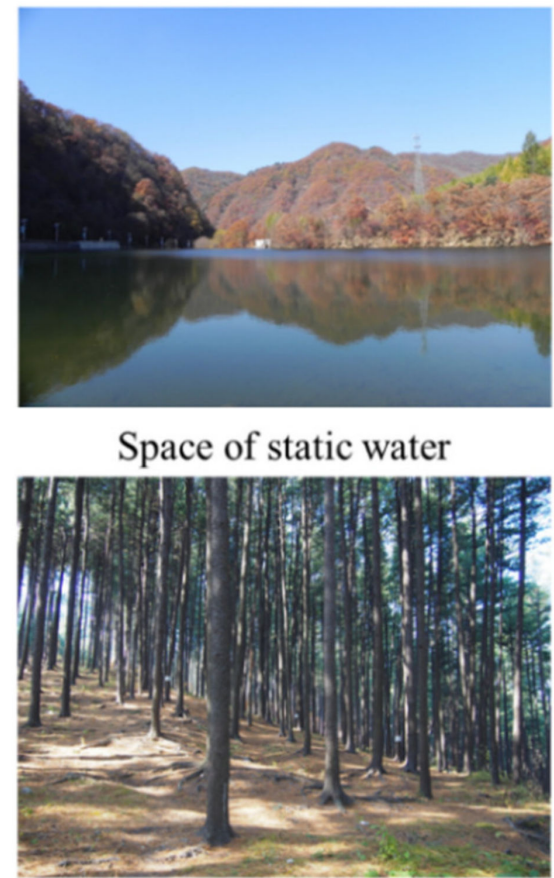

Space of coniferous landscape

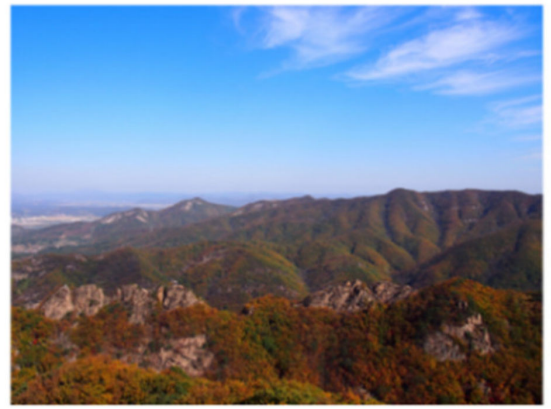

Space of lookout

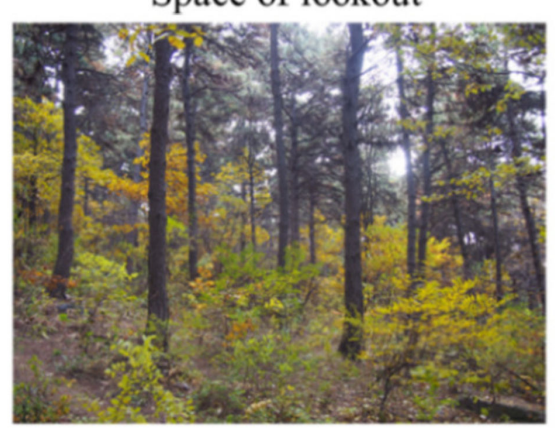

Space of mixed landscape

Figure 2. Experimental materials. This figure was created by Yu Gao (Shenyang Agricultural University).

\subsection{Participating Subjects}

First, a study by Wang et al. [48,49] showed that 18 to 35 -year-old tourists are the main participants in forest park tourism and have an absolute advantage.

Second, a study by Guo et al., indicated that students have the corresponding (a certain degree) ability to judge landscape aesthetics (including recreational perception). At the same time, it was feasible and representative to select students to conduct related experiments in landscape research [32,50-52].

Therefore, in our experiments of eye-tracking and perception questionnaires, undergraduate and postgraduate students from Shenyang Agricultural University were recruited as our experiment participants.

The participants recruited in our survey were all voluntarily participating in the experiment, and their naked or corrected vision is above 1.0, and there are no other eye diseases (color blindness, etc.). During our experiments, we required participants to clean their eyes, not to wear cosmetic contact lenses, no eyeliner and so on. In addition, in order to allow participants to view the experimental material more naturally, the participant's head is not restricted during the experiment. However, they were asked to avoid sudden head movements to ensure that accurate eye movement data could be obtained [47].

\subsection{Experimental Procedure and Selection of Indicators}

The experiments in this study are mainly divided into two parts. All experiments are carried out in batches in the eye movement laboratory of our school. The details are as follows:

Part 1: Eye-tracking experiment

Before the start of the experiment, the participant wore an SMI Glass2 eye-tracker, sat $3 \mathrm{~m}$ directly in front of the screen, and used a five-point calibration. After calibration, the participant began to watch 6 experimental pictures and 5 blank photos on a $1.4 \mathrm{~m} \times 1.9 \mathrm{~m}$ screen using a projector (Model: EPSON XGA2800, Resolution: $1024 \times 768$ ). The eye movement data of a single person lasted about $120 \mathrm{~s} /$ person (Figure 3). 
A

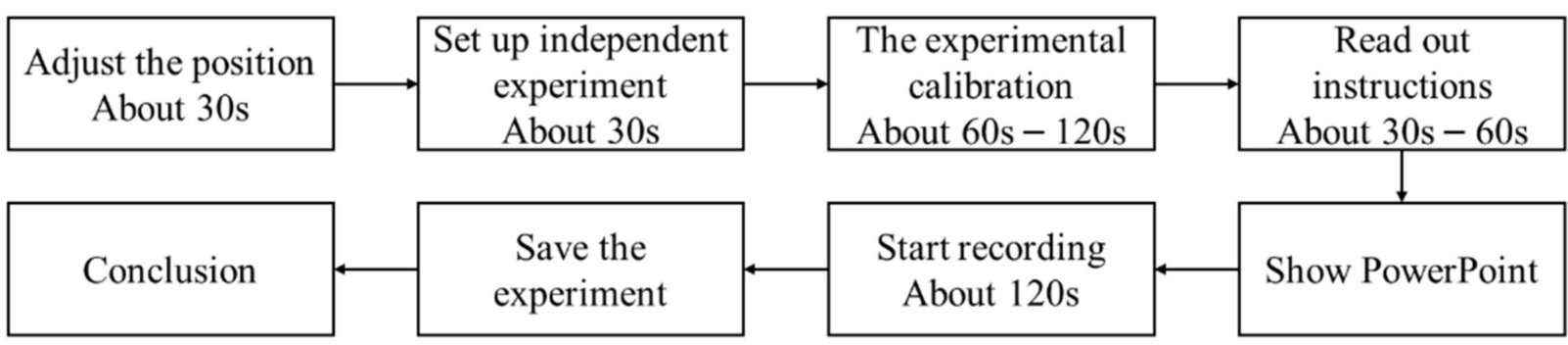

B

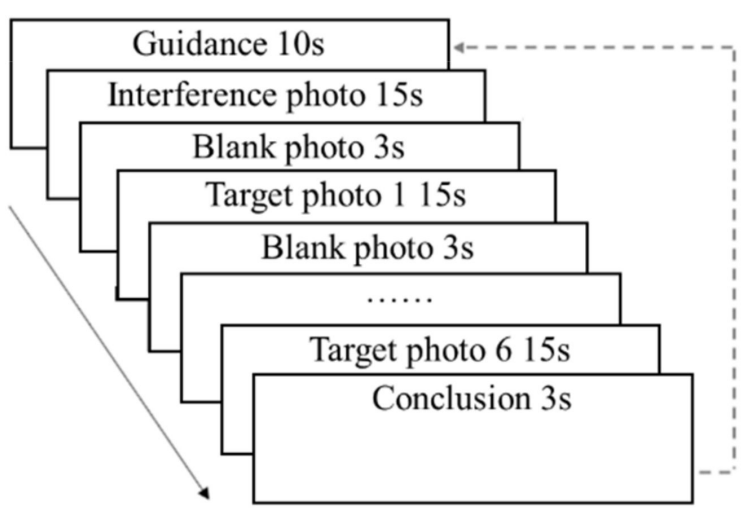

$\mathrm{C}$

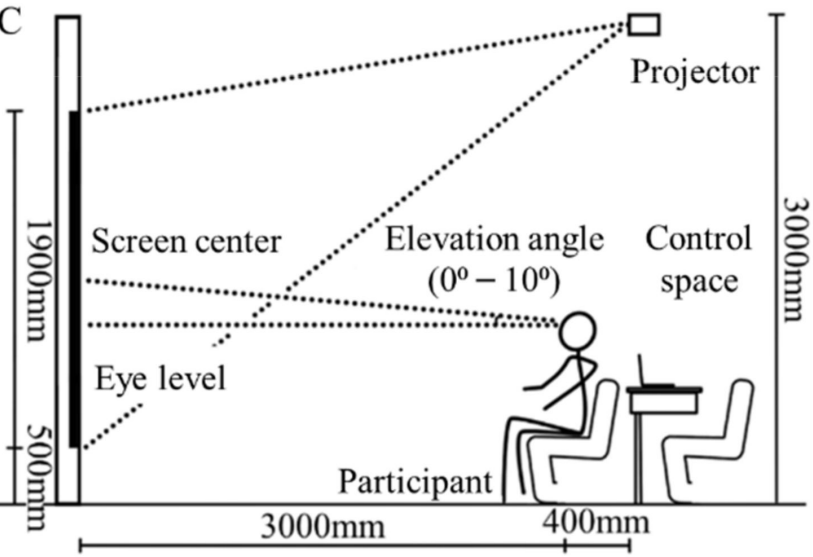

Figure 3. Schematic diagram of the experiment. (A): Experimental flow chart in the eye-tracking experiment. (B): PowerPoint playback diagram of the eye-tracking experiment. (C): Participants' view schematic of the eye-tracking experiment. This figure was created by Yu Gao (Shenyang Agricultural University).

This part of the experiment is mainly to obtain the indicators of average fixation duration, average fixation count, average lateral visual span, average portrait visual span and average pupil diameter of the participant when appreciating the space of different forest landscape $[6,29,46,47,53-55]$, see details in Table 1.

Table 1. Eye movement indicators and meanings.

\begin{tabular}{ll}
\hline \multicolumn{1}{c}{ Eye Movement Indicators } & \multicolumn{1}{c}{ Meanings } \\
\hline Average fixation duration & Average length of fixation generated by participants viewing each landscape image. \\
\hline Average fixation count & Average number of fixations generated by participants viewing each landscape image. \\
\hline Average lateral visual span & Effective visual range obtained by participants gazing horizontally at each landscape picture. \\
\hline Average portrait visual span & Effective visual range obtained by participants gazing vertically at each landscape picture. \\
\hline Average pupil diameter & Average value of the change in pupil size when participants viewed each landscape picture. \\
\hline
\end{tabular}

Part 2: Cognitive Questionnaire

After the eye-tracking experiment, the participant follows the relevant personnel to another laboratory to conduct related cognitive investigations. In this laboratory, we will show 6 experimental materials again, and participants will fill in the corresponding cognitive questionnaire for each picture.

The questionnaire showed 4 first-level and 10 s-level indicators (Table 2). All the questions are scored using the 7-point Likert scale, where 1 point represents the worst and 7 represents the best [56,57]. Finally, the single-person cognitive questionnaire data lasted about $230 \mathrm{~s} /$ person. 
Table 2. Psychological perception evaluation indicators.

\begin{tabular}{|c|c|c|c|c|}
\hline Category & & Evaluation & ndicators & \\
\hline Landscape change & $\begin{array}{l}\text { Whether the plant } \\
\text { species are diverse }\end{array}$ & $\begin{array}{l}\text { Whether the landscape } \\
\text { content is changing }\end{array}$ & $\begin{array}{l}\text { Whether the } \\
\text { near-middle landscape } \\
\text { is three-dimensional }\end{array}$ & \\
\hline Color & Whether the color is rich & $\begin{array}{l}\text { Whether the } \\
\text { color is bright }\end{array}$ & & \\
\hline Space & $\begin{array}{l}\text { Whether the } \\
\text { space is open }\end{array}$ & $\begin{array}{l}\text { Can you see the } \\
\text { distant landscape }\end{array}$ & $\begin{array}{l}\text { Whether the } \\
\text { space is neat }\end{array}$ & $\begin{array}{l}\text { Whether the space has } \\
\text { a sense of hierarchy }\end{array}$ \\
\hline Overall & $\begin{array}{l}\text { Whether you are satisfied } \\
\text { with it }\end{array}$ & & & \\
\hline
\end{tabular}

\subsection{Statistics and Analysis}

In this study, first, the analysis software of SMI BeGaze 3.7 was used to deal with the original eye movement data, which was generated in the first part of the experiment (eye-tracking experiment).

Second, we used SPSS 23.0 to analyze the spatial cognition factors that affect the participant's visual behavior and satisfaction preferences when viewing forest recreation landscapes. The frame is shown in Figure 4.

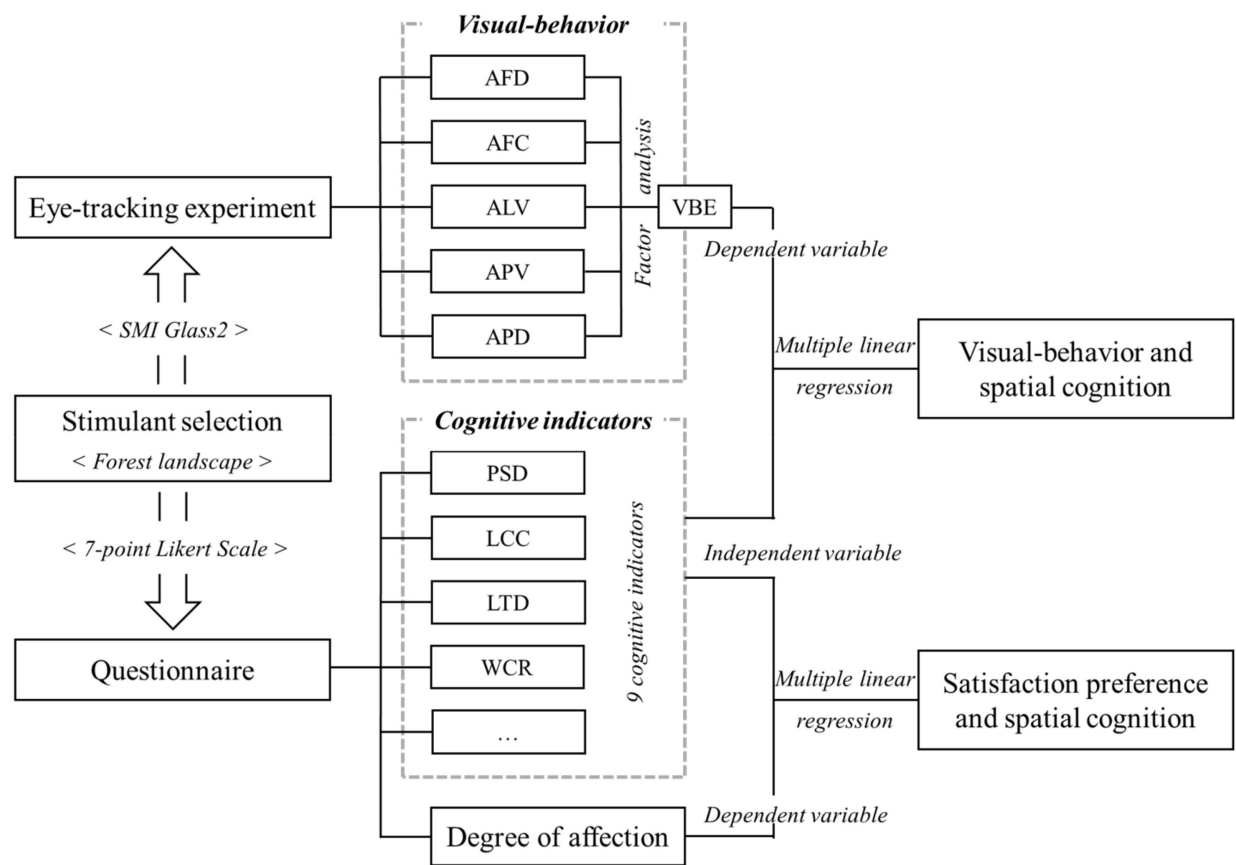

Figure 4. Research framework. Note: AFD: average fixation duration; AFC: average fixation count; ALV: average lateral visual span; APV: average portrait visual span; APD: average pupil diameter; PSD: whether the plant species are diverse; LCC: whether the landscape content is changing; LTD: whether the near-middle landscape is three-dimensional; WCR: whether the color is rich; VBE: the evaluation of visual behavior. This figure was created by Yu Gao (Shenyang Agricultural University).

Then, we test the normal distribution of the experimental data, and the dataset investigated was normally distributed in this study.

Based on the above, the steps of our analysis are as follows:

(1) To analyze participants' visual behavior as a whole, we used factor analysis in SPSS 23.0. Five eye movement indicators (the average fixation duration, average fixation count, average lateral visual span, average portrait visual span and average pupil 
diameter) were taken as variables to calculate the visual-behavior evaluation value of each forest recreation landscape space. The formula is [58]:

$$
V B E=\left(F_{x 1} * V_{x 1}+F_{x 2} * V_{x 2}+\ldots+F_{x n} * V_{x n}\right) /\left(F_{x 1}+F_{x 2}+\ldots+F_{x n}\right)
$$

$V B E$ refers to the evaluation of visual behavior, $F_{x n}$ refers to the factor score of a certain eye movement indicator, and $V_{x n}$ is the variance contribution rate of the eye movement indicator after factor analysis.

(2) To analyze the spatial perception factors that affect the participant's visual behavior and evaluation of satisfaction preference in forest recreation landscape space, we used the stepwise multiple linear regression analysis in SPSS 23.0. The visual-behavior evaluation value and satisfaction preference were taken as the dependent variables. The participant's psychological cognition evaluation indicator for the forest recreation landscape space was used as the independent variable. Equation models that affect the participants', who viewed the forest recreation landscape space, evaluation of visual behavior and satisfaction preference are established.

(3) To further explore the spatial perception factors that affect visual behavior and satisfaction preferences in different professional backgrounds and different spatial types, we use the multiple linear regression analysis in SPSS 23.0 to establish spatial perception equation models that affect participant's visual behavior and satisfaction preferences under different professional backgrounds (independent variable: spatial perception indicator; dependent variable: visual behavior and satisfaction preferences of participants majoring in landscape and non-landscape). Spatial perception equation models that affect participant's visual behaviors and satisfaction preferences in different types of forest recreation landscape spaces (independent variable: spatial perception indicator; dependent variable: visual behaviors and satisfaction preferences in six types of forest recreational landscape spaces).

\section{Results}

In this survey, a total of 60 undergraduates and postgraduates of different majors were recruited, all of whom were 18-24 years old, and finally 53 valid data were obtained. The ratio of male to female is about 1:0.89, and landscape majors to non-landscape majors is 1:0.83. The non-landscape majors mainly include forestry, horticulture, economic management, land and environment, etc., see Table 3.

Table 3. Participants' attributes. SWD: the space of dynamic water; SSW: the space of static water; SLO: the space of lookout; SBF: the space of broadleaf forest landscape; SCF: the space of coniferous forest landscape; SMF: the space of mixed forest landscape.

\begin{tabular}{|c|c|c|c|c|c|c|c|}
\hline & & SWD & SSW & SLO & SBF & SCF & SMF \\
\hline \multirow{2}{*}{ Sex } & Male & $28(52.8 \%)$ & $28(52.8 \%)$ & $28(52.8 \%)$ & $28(52.8 \%)$ & $28(52.8 \%)$ & $28(52.8 \%)$ \\
\hline & Female & $25(47.2 \%)$ & $25(47.2 \%)$ & $25(47.2 \%)$ & $25(47.2 \%)$ & $25(47.2 \%)$ & $25(47.2 \%)$ \\
\hline \multirow{2}{*}{ Major } & Landscape & $29(54.7 \%)$ & $29(54.7 \%)$ & $29(54.7 \%)$ & $29(54.7 \%)$ & $29(54.7 \%)$ & $29(54.7 \%)$ \\
\hline & Non-landscape & $24(45.3 \%)$ & $24(45.3 \%)$ & $24(45.3 \%)$ & $24(45.3 \%)$ & $24(45.3 \%)$ & $24(45.3 \%)$ \\
\hline & $\mathrm{n}$ & 53 & 53 & 53 & 53 & 53 & 53 \\
\hline
\end{tabular}

\subsection{Participants' Visual Behavior and Satisfaction Preferences in the Forest Recreation Landscape Space}

First, we used a formula (1) to calculate the value of the participant's visual-behavior evaluation of the scene based on 5 indicators of eye movement, including the participant's average fixation duration, average fixation count, average lateral visual span, average portrait visual span and average pupil diameter, and we counted the participant's satisfaction preferences for each forest recreational landscape space, see Table 4. 
Table 4. Participants' visual behavior and satisfaction preference in forest recreation landscape space. AFD: average fixation duration; AFC: average fixation count; ALV: average lateral visual span; APV: average portrait visual span; APD: average pupil diameter; VBE: the evaluation of visual behavior; WSA: Whether you are satisfied with it.

\begin{tabular}{|c|c|c|c|c|c|c|c|}
\hline & AFD & AFC & ALV & APV & APD & VBE & WSA \\
\hline Space of dynamic water & 9884.908 & 38.264 & 475.385 & 308.378 & 3.966 & 0.610 & 5.887 \\
\hline Space of static water & 9874.469 & 37.642 & 423.121 & 187.736 & 3.377 & -33.200 & 5.604 \\
\hline Space of lookout & $10,133.161$ & 36.962 & 555.897 & 243.051 & 3.982 & -5.790 & 4.830 \\
\hline Space of broadleaf forest landscape & 9744.997 & 38.434 & 569.897 & 329.817 & 4.166 & 15.150 & 3.226 \\
\hline Space of coniferous forest landscape & 9615.649 & 37.208 & 590.422 & 334.872 & 3.962 & 10.780 & 4.094 \\
\hline Space of mixed forest landscape & 9546.928 & 36.000 & 618.187 & 375.978 & 3.812 & 12.370 & 3.472 \\
\hline
\end{tabular}

From Table 4, we can see:

(1) Ranking of participant's visual-behavior evaluation values: the space of broadleaf forest landscape $(15.15)>$ mixed forest landscape space $(12.370)>$ the space of coniferous forest landscape $(10.780)>$ the space of dynamic water $(0.610)>$ the space of lookout $(-5.790)>$ the space of static water $(-33.200)$;

(2) Ranking of participant's satisfaction preference evaluation: the space of dynamic water $(5.887)>$ the space of static water $(5.604)>$ the space of lookout $(4.830)>$ the space of coniferous forest landscape $(4.094)>$ the space of mixed forest landscape (3.472) > the space of broadleaf forest landscape (3.226).

Second, we performed a difference analysis (pairwise comparison) of the participant's eye-movement indicator, visual-behavior evaluation value and satisfaction preference in each forest recreational landscape space and obtained the results shown in Figure 5.
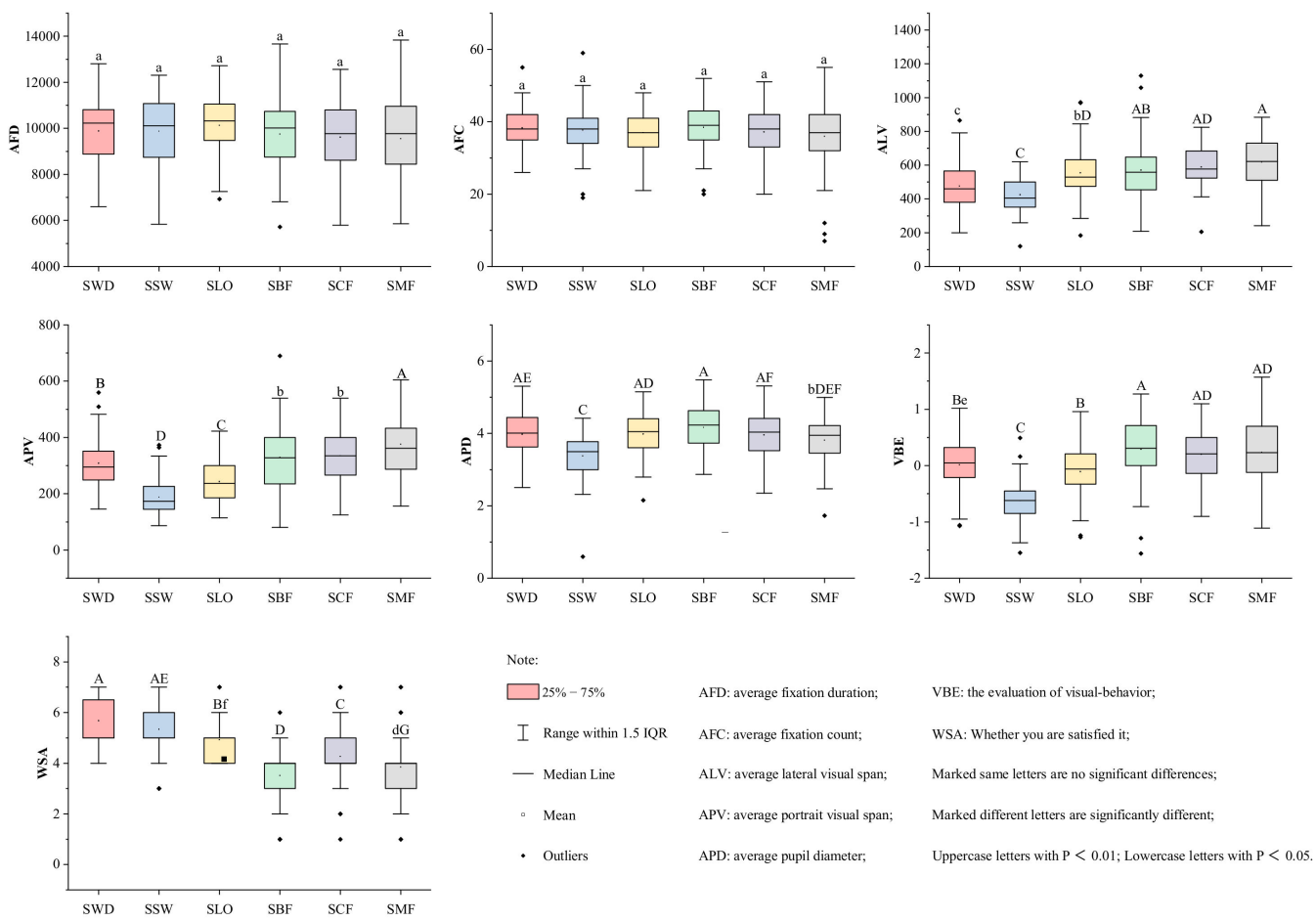

Figure 5. Differences in participant's visual behavior and satisfaction preference in forest recreational landscape space. This figure was created by Yu Gao (Shenyang Agricultural University).

From the analysis in Figure 5, we can see:

(1) There are significant differences in participant's visual behavior in different types of forest recreational landscape spaces $(p<0.05)$, and the difference is mainly reflected in the indicator of visual span. 
Participant's visual behavior showed no significant difference in the in-forest landscape space with different spatial attributes $(p>0.05)$, but there were significant differences in the water landscape space with different attributes $(p<0.01)$.

(2) Participant's satisfaction preferences have significant differences among different types of forest recreational landscape spaces $(p<0.05)$, and people prefer forest water landscape spaces.

Finally, we visualized the location and time of the participants' fixation when viewing forest landscape space to obtain a landscape focus map (Figure 6). This figure shows that there are significant differences in the landscape elements and degree of attention of the participants when appreciating different types of forest waterscape space. However, as a whole, participant's visual behavior of the space of the in-forest landscape is scattered and more concentrated in the water landscape space.

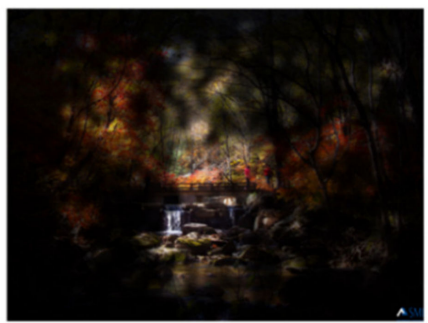

Space of dynamic water

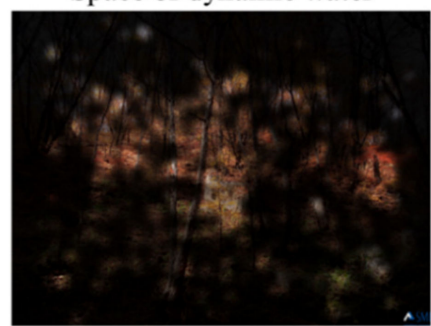

Space of broadleaf landscape

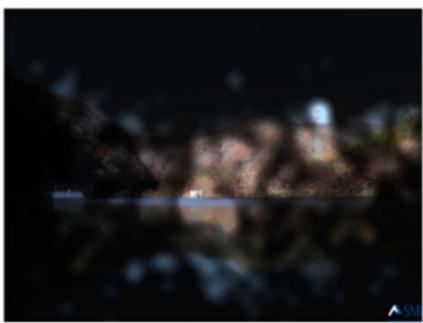

Space of static water

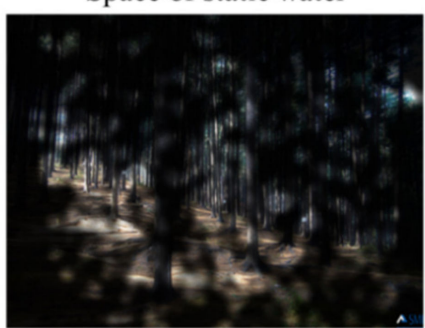

Space of coniferous landscape

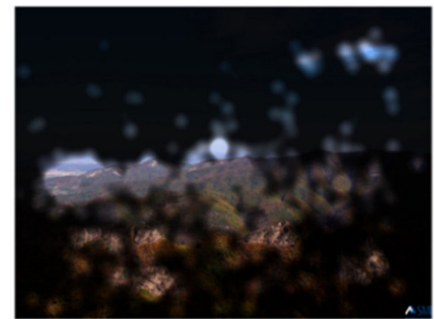

Space of lookout

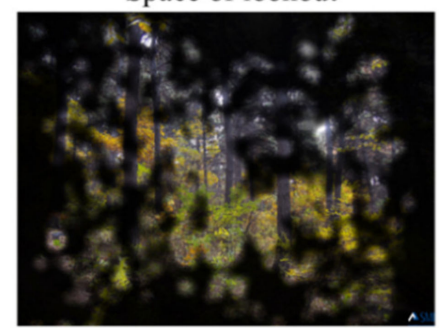

Space of mixed landscape

Figure 6. Focus map of different forest recreation landscape spaces. This figure was created by Yu Gao (Shenyang Agricultural University).

That is, places where the participants demonstrate more frequent visual behavior have relatively lower satisfaction preferences. In addition, the visual behavior of in-forest landscape space is more frequent than water landscape space. This result shows that the participants' perception of forest landscape space does not always prefer those "positive" spaces, and "disordered" spaces may also attract people's attention.

In addition, after participants explore places, they have a higher "interest" in the local elements of scenes (such as buildings). Therefore, their attention is more inclined to observe a few important landscape elements and local areas, and the degree of visual wandering is not high. However, due to the scattered distribution of trees in the space of the in-forest landscape, participants focus on searching for "interesting" elements in a wide range when exploring the scene, so that they have higher visual attention, especially on the eye-movement indicator of visual span.

\subsection{Spatial Cognition Factors That Affect Participants' Visual Behaviors and Satisfaction Preferences for Forest Recreation Landscape Space}

To explore the main factors of spatial perception that affect participants' visual behavior and satisfaction preferences, we use the evaluation value of visual behavior and satisfaction preference as the dependent variables, and the space type and other spatial perception indicators as independent variables. The results of multiple linear regression analysis conducted within SPSS 23.0 are shown in Figure 7. 


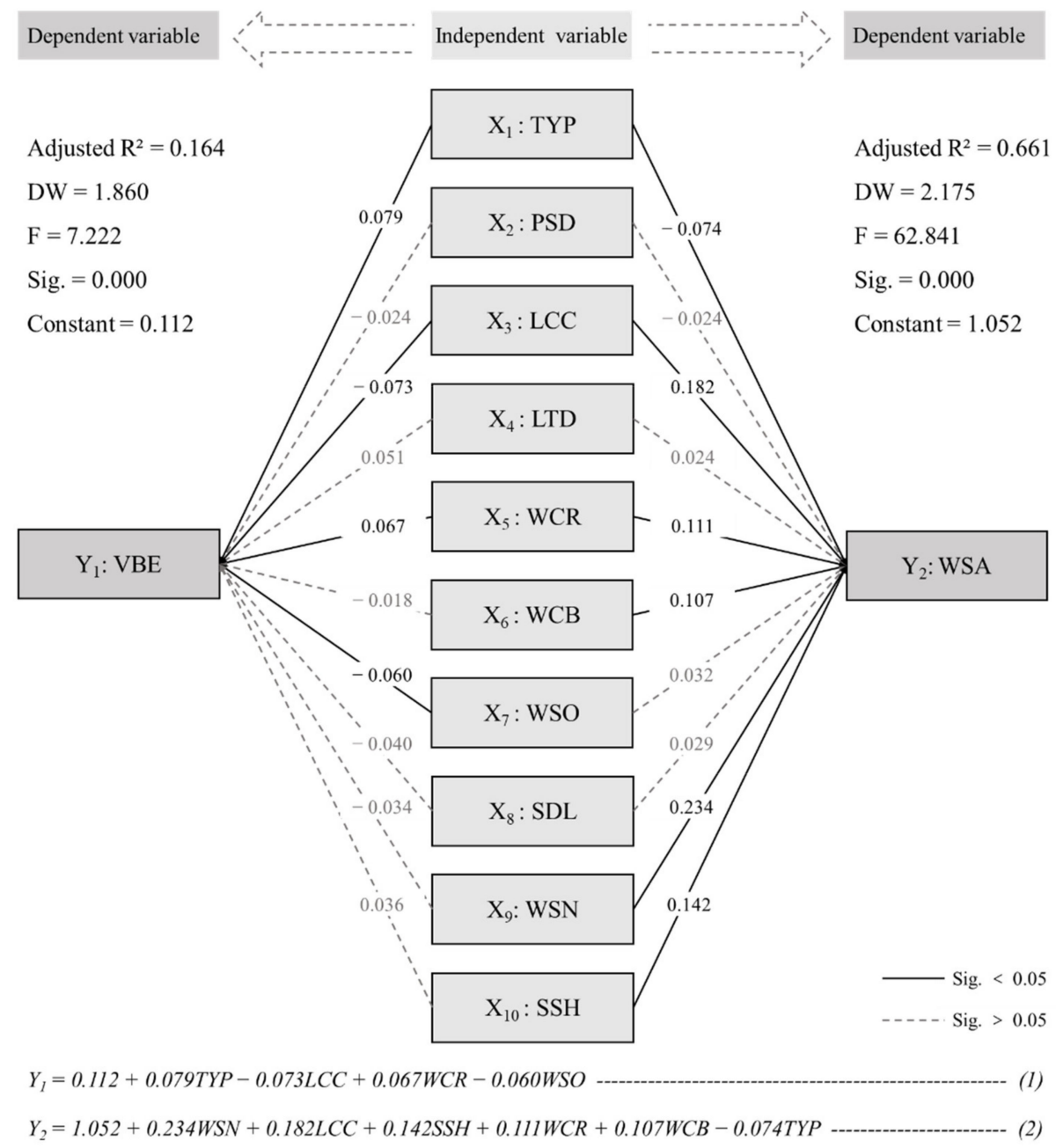

Figure 7. Spatial perception factors that affect visual behavior and satisfaction preference for forest recreation landscape space. Note: TYP: forest recreation landscape spatial type; PSD: whether the plant species are diverse; LCC: whether the landscape content is changing; LTD: whether the near-middle landscape is three-dimensional; WCR: whether the color is rich; WCB: whether the color is bright; WSO: whether the space is open; SDL: can you see the distant landscape; WSN: whether the space is neat; SSH: whether the space has a sense of hierarchy; VBE: the evaluation of visual behavior; WSA: Whether you are satisfied it. This figure was created by Yu Gao (Shenyang Agricultural University).

First, Figure 7 shows the adjusted $\mathrm{R}^{2}=0.164, p=0.000$ of the model of visual-behavior evaluation under the forest recreation landscape from the spatial psychological perception evaluation and the adjusted $\mathrm{R}^{2}=0.661, p=0.000$ of the model of satisfaction preference under the forest recreation landscape from the spatial psychological perception evaluation. These results mean that the interpretation rates of the forest recreation landscape visualbehavior evaluation and satisfaction preference model are $16.4 \%$ and $66.1 \%$, respectively, and the model is significant.

Then, the four indicators of the type of forest recreation landscape space (TYP), landscape content (LCC), color richness (WCR) and spatial openness (WSO) have a substitute relationship with visual behavior and have multiple linear correlations; the six indicators, namely forest recreation landscape space type (TYP), rich landscape content (LCC), color richness (WCR), color brightness (WCB), spatial regularity (WSN), and spatial sense of hierarchy $(S S H)$, have a substitute relationship with scene satisfaction and have multiple linear correlations. The model is tested, and the F values are far greater than 1. 
Model (1) — the model of participants' visual-behavior evaluation-shows that factors including the space type, landscape richness, color richness and spatial openness are important for visual quality when participants appreciate the space of forest recreation landscape. Additionally, when the richness of the landscape content in the scene is low, the richer the color, and the closed space of the place can attract the participants' visual attention.

The reason may be that the participants try to find more "interesting" landscape information after understanding the space with less landscape information, thereby producing a higher visual-behavior evaluation of the landscape.

Model (2) — the model of participant's satisfaction preference evaluation-shows that spatial regularity, landscape content richness, spatial hierarchy, color richness, color brightness and spatial type are important factors that have a significant impact on the participant's satisfaction preference when appreciating the space of forest recreation landscape. Additionally, participants were inclined to be satisfied with the neat space, rich landscape content, strong sense of hierarchy, rich colors and bright forest landscape water space. Satisfaction preference for the space of in-forest landscape is relatively low, especially for mixed forest landscape spaces.

That is, we need to improve the tidiness, the richness of the landscape content, the sense of hierarchy (such as arbor + shrub + grass), color richness and brightness and other psychological perception indicators of mixed forest landscape space, which can improve participants' satisfaction preference in the space of mixed forest landscape.

\subsection{Spatial Cognition Factors Affecting Visual Behavior and Satisfaction Preferences of Participants in Different Professional Backgrounds and Different Types of Forest Recreation Landscape Spaces}

3.3.1. Spatial Cognition Factors That Affect the Visual Behavior and Satisfaction Preference of Participants in Different Professional Backgrounds

To further analyze whether the presence of professional knowledge will affect participants' perception of forest recreation landscape space, first, we divided all participants (53) into landscape major (29) and non-landscape major (24) based on their professional knowledge background. Then, we used participants' visual-behavior evaluation value and satisfaction preference as dependent variables and used the spatial type and spatial cognitive indicators as independent variables through the input in the multiple linear regression analysis in SPSS 23.0, which is shown in Figure 8.

First, Figure 8 shows the adjusted $\mathrm{R}^{2}=0.155, p=0.000$ of the model of the participants of landscape from the visual-behavior evaluation under the forest recreation landscape spatial psychological perception evaluation and the adjusted $R^{2}=0.266, p=0.000$ of the model of the participants of non-landscape. The model of the landscape for participants satisfaction preference under the forest recreation landscape from the spatial psychological perception evaluation have an adjusted $\mathrm{R}^{2}=0.683, p=0.000$, and the model of nonlandscape for participants have an adjusted $\mathrm{R}^{2}=0.635, p=0.000$. Meanwhile, the F values of each model are far greater than 1 . That is, these models are valid and significant.

Second, from the Model (3) — the model of participants' visual-behavior evaluation of landscape - shows that factors of landscape content (LCC), spatial openness (WSO), color richness (WCR), and the type of forest recreation landscape space (TYP) have a significant impact on participants' visual behavior of landscape when they view the forest recreation landscape space.

Model (4) — the model of participants' visual-behavior evaluation of non-landscapeshows that factors of spatial transparency $(S D L)$, plant species (PSD), spatial regularity (WSN), the type of forest recreation landscape space (TYP) and the three-dimensional sense of landscape (LTD) have a significant impact on their visual behavior.

That is, for the participants of landscape, the low-opening, simple, but colorful space can attract the visual attention of the group of landscape. The higher regularity, the spatial hierarchy and the close-up space with fewer plant species can attract the visual attention of the group of non-landscapes. 


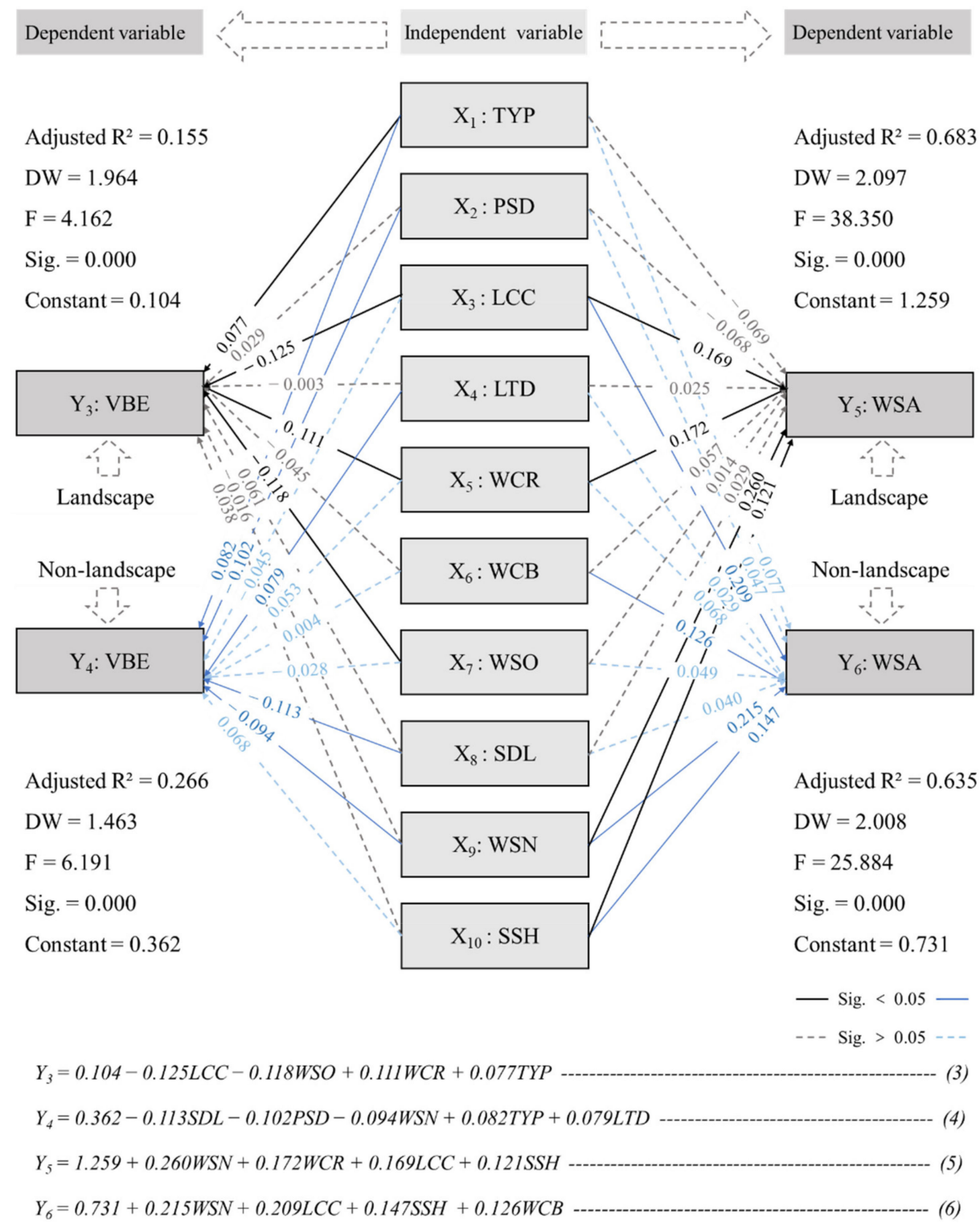

Figure 8. Spatial perception factors that influence the visual behavior and satisfaction preferences of participants in different professional backgrounds in the forest recreation landscape space. Note: TYP: forest recreation landscape spatial type; PSD: whether the plant species are diverse; LCC: whether the landscape content is changing; LTD: whether the near-middle landscape is three-dimensional; WCR: whether the color is rich; WCB: whether the color is bright; WSO: whether the space is open; SDL: can you see the distant landscape; WSN: whether the space is neat; SSH: whether the space has a sense of hierarchy; VBE: the evaluation of visual behavior; WSA: Whether you are satisfied with it. This figure was created by Yu Gao (Shenyang Agricultural University).

From these results, we know that the presence of professional knowledge affects the participants' visual attention to the forest recreation landscape space from the level of psychological cognition. In addition, we found an interesting phenomenon; factors of landscape content ( $L C C$ ) and plant species (PSD), both have a negative contribution to the evaluation of visual behavior. Based on this point, we believe that the excessively complex space design in the forest recreation landscape brings low visual evaluation to people.

Then, from Model (5) — the model of participants' satisfaction preference of landscapeand Model (6) — the model of participants' satisfaction preference evaluation of landscapewe found a very interesting result; indicators of spatial regularity (WSN), rich landscape content (LCC) and hierarchy (SSH) have a significant impact on the satisfaction prefer- 
ences of the group of landscape and non-landscape majors. However, the degree of their influence varies.

Meanwhile, we found that participants from both landscape and non-landscape majors are affected by the colors in the scene, but participants with a background of landscape are more affected by the color richness (WCR) of the space in their satisfaction preference evaluation.

That is, the evaluation indicators that affect participants' satisfaction with forest recreation landscape space under different professional backgrounds are basically the same, but the degree of impact of these indicators on participants with professional backgrounds is different, especially the indicators of color (WCR and WCB), and participants of landscape majors have a stronger awareness of color, which is mainly reflected in color richness (WCR). We agree that the main reason for this result is the "professional effect".

3.3.2. Spatial Cognition Factors That Affect the Visual Behavior and Satisfaction Preference of Participants in Different Types of Forest Recreation Landscape Spaces

From Model (1) — the model of participant's visual-behavior evaluation-and Model (2) - the model of participant's satisfaction preference evaluation-we find that the type of forest recreation landscape space $(T Y P)$ has a significant impact on participants' visual behavior and satisfaction preferences. To explore the spatial perception factors and differences in different types of forest recreation landscape spaces that affect participant's visual behavior, we use the stepwise multiple linear regression analysis in SPSS 23.0. To establish the visual behavior and satisfaction preference models for different forest recreation landscape spaces, the visual behavior and satisfaction preference in each type of forest recreation landscape are taken as the dependent variables, and the spatial perception indicator of each forest recreation landscape space are taken as the independent variables. The results show that the $p$ value $(p<0.05)$ of each model is significant, and there is a substitute relationship between the spatial perception indicators. Each model is tested; the F value is far greater than 1 , see Table 5.

Table 5. Spatial perception factors affecting visual behavior and satisfaction preferences in different types of forest recreation landscape spaces. SWD: the space of dynamic water; SSW: static water space; SLO: the space of lookout; SBF: the space of broadleaf forest landscape; SCF: coniferous forest landscape space; SMF: mixed forest landscape space; VBE: the evaluation of visual behavior; WSA: Whether you are satisfied with it.

\begin{tabular}{clcccc}
\hline Type & \multicolumn{1}{c}{ Regression Equation } & Adjusted $\mathbf{R}^{2}$ & F & DW & $p$ \\
\hline \multirow{2}{*}{ SWD } & $V B E=-0.693+0.128 S S H$ & 0.118 & 6.805 & 1.884 & 0.012 \\
& $W S A=0.751+0.258 S S H+0.301 W C B+0.135 S D L+0.171 W C R$ & 0.505 & 14.285 & 2.182 & 0.000 \\
\hline \multirow{2}{*}{ SSW } & $V B E=-1.282+0.117 L T D$ & 0.082 & 5.662 & 1.947 & 0.021 \\
& $W S A=1.031+0.510 L C C+0.301 W S N$ & 0.433 & 20.830 & 2.109 & 0.000 \\
\hline \multirow{2}{*}{ SLO } & $V B E=0.363-0.154 W S N+0.119 S D L-0.082 P S D$ & 0.281 & 7.767 & 1.899 & 0.000 \\
& $W S A=1.817+0.197 S S H+0.164 W S N+0.136 W C B+0.135 L C C$ & 0.386 & 9.180 & 2.032 & 0.000 \\
\hline \multirow{2}{*}{ SBF } & $V B E=0.737-0.134 W S O$ & 0.064 & 4.576 & 1.778 & 0.037 \\
& $W S A=0.975+0.172 S S H+0.383 W C R+0.212 W S N$ & 0.519 & 19.671 & 2.355 & 0.000 \\
\hline \multirow{2}{*}{ SCF } & $E M E=0.464-0.092 L C C$ & 0.052 & 3.836 & 2.191 & 0.046 \\
& $W S A=0.046+0.466 W S N+0.345 L C C+0.172 W C B$ & 0.626 & 29.973 & 2.322 & 0.000 \\
\hline \multirow{2}{*}{ SMF } & $E M E=0.698-0.207 S D L+0.250 W S O-0.136 L C C$ & 0.255 & 6.932 & 2.751 & 0.001 \\
& $W S A=1.494+0.374 W S O+0.372 W S N$ & 0.437 & 21.195 & 1.886 & 0.000 \\
\hline
\end{tabular}

Table 5 shows that in different forest recreation landscape space, there are differences in the elements of spatial perception that affect participants' visual behavior and satisfaction preference.

First, as a whole, the elements of spatial perception that significantly affect the participants' visual behavior and satisfaction preferences in the space of dynamic water are the 
sense of layering $(S S H)$, color brightness $(W C B)$, transparency $(S D L)$, color richness $(W C R)$; in static water space, they are the three-dimensional sense of landscape (LTD), landscape content richness (LCC) and spatial regularity (WSN); in the space of lookout, they are the spatial regularity $(W S N)$, transparency $(S D L)$, plant species (PSD), layering ( $S S H)$, color brightness (WCB) and landscape content richness (LCC); in the space of broadleaf forest landscape, they are the openness (WSO), layering (SSH), color richness (WCR) and spatial regularity (WSN); in the space of coniferous forest landscape, they are the landscape content richness (LCC), spatial regularity (WSN) and color brightness (WCB); in mixed forest landscape space, they are the transparency $(S D L)$, openness (WSO), landscape content richness (LCC) and spatial regularity (WSN).

Then, we found the elements in forest waterscape space are the same, but the spatial perception factors that affect the participants' visual behavior and satisfaction preference are different. At the same time, the spatial perception factor of hierarchy $(S S H)$ in the space of dynamic water jointly affects the participants' visual behavior and satisfaction preference. The spatial regularity $(W S N)$ in the space of lookout simultaneously affects the participants' visual behavior and satisfaction preferences. The spatial perception factors that impact the participants' visual behavior and satisfaction preferences for the space of the in-forest landscape with different characteristics are also different. The perception of visual behavior and satisfaction preferences in the space of coniferous forest landscape is due to the landscape richness, and in the space of mixed forest landscape is the spatial openness.

That is, even when the elements in different types of recreation landscape space are similar, the factors that affect people's visual-behavior characteristics and overall cognitive evaluation also present differences.

In addition, the analysis result shows that to improve participants' satisfaction with the scene in different types of forest recreation landscape spaces and promote their "active" visual behavior, there are different perception factors of forest landscape space that need to be improved. Therefore, we can use the characteristics of the scene itself to improve the spatial perception factors, thereby increasing the satisfaction of the scene and reducing participant's unnecessary visual behavior in the scene, so that they can search interesting elements for the scene in a short time and attract participant's attention.

\section{Discussion}

As we mentioned earlier, the evaluation of visitor satisfaction preferences is a subjective factor of long-term cognitive health [9]. In the process of exploring the impact of the forest recreational environment on people's satisfaction preference assessment, eyes (visual behavior) are the main medium for forming visitor's spatial judgments [59]. As Kaplan points out, in landscape management and planning, "understanding" often equals "seeing", and people tend to make judgments based on what they see. Our results support the thesis that the visual behavior and satisfaction preferences of forest landscape space experiencers are influenced by the type of space. The richness of the content and the richness of color in the scene act on both psychological assessment and visual behavior [60].

In addition, our research also found that differences in tourists' professional backgrounds in the experience of forest landscape resources also affect their focus on evaluating and appreciating forest landscape space. Kaplan's information processing theory also explains our findings; humans' ability to understand their environment and what is going on in it depends, in part, on prior knowledge or experience. We speculate that the reason for this phenomenon may be the result of the "professional effect" of different participants" educational backgrounds with different attributes [61].

\subsection{Relationship between the Satisfaction Preferences of the Scene and the Evaluation of Visual Behavior}

In our research, we found that scenes with higher satisfaction preferences may not necessarily have higher visual-behavior evaluations (Table 4, Figure 6). This result is consistent with previous studies pointing out that low-information stimuli do not seem to bring the weakest visual effects; on the contrary, these landscapes seem to trigger a wider 
visual exploration [47]. The same research also pointed out that people's perception of an image's attention (higher visual behavior) has nothing to do with the likeness of the image [62].

At the same time, participants had more frequent visual behavior when viewing in-forest landscapes with lower informational content than water landscapes. On the contrary, the satisfaction preference of the in-forest landscape is lower than that of the water landscape. We speculate that the reasons for this result are mainly as follows:

(1) Participants' perception of forest recreation landscape space does not always prefer those "active" spaces, and those "disordered" spaces may also attract people's attention. The reason may be that compared to the "orderly" urban landscapes that they usually encounter, people prefer or enjoy the messy and natural beauty brought by forest landscapes when they appreciate such landscapes, which leads to more visual behaviors.

(2) Because the informational content of the in-forest landscape is simpler than the forest water landscape, people devote themselves to looking for objects that they think are interesting when appreciating the space of the forest landscape. That is, when appreciating the space of forest landscape, participants pay attention to a large-scale search for "interesting elements", resulting in higher visual behavior. This study also validated the findings of Stamps et al. [63], stimuli with lower informational content are usually boring, and people will look for interesting objects, which will trigger a wider range of visual exploration.

However, in forest waterscape space, the participants' vision was attracted by the water body and landmark buildings. To explore the local details of the scene, the degree of visual wandering was low, resulting in lower visual behavior, especially in the visual span. As Cottet [45] pointed out, among all the objects that comprised the landscape, the river attracted the greatest participants' visual attention.

\subsection{Factors That Affect Visual Behavior When Viewing the Scene}

First, Khachatryan et al. [64] confirmed that visual attractiveness was highest in heterogeneous landscapes (that is, composed of turfgrass and plants) and lowest in homogeneous landscapes (that is, mainly composed of turfgrass or plants), which showed an opposite trend to the results of this study; the contribution of landscape abundance to the evaluation of visual behavior was negative $(-0.073)$, which means that the scene with richer landscape content (higher landscape heterogeneity) produced a lower evaluation value of visual behavior (Figure 7).

We speculate that the main reason for this difference is that Khachatryan's research further explored the relationship between landscape aesthetics and maintenance perception by changing the types and proportions of plants in the landscape. However, in our research, we chose different types of forest recreation landscapes. In the low landscape abundance of in-forest landscape space, participants will always look for objects they think interesting, or participants think there are fewer "interesting elements" in the scene. Therefore, they will explore the recreation landscape space more to discover more and interesting information, thereby resulting in "negative" visual behavior, especially in the eye movement indicator of visual span (Table 4). In water landscape space with high landscape richness, although the amount of information contained in the scene is relatively large, the participants are directly attracted by the "interesting elements" (water bodies, landmark buildings, or a combination of landscape stones) in the scene; that is, in the water landscape space, the participants are more involved in local exploration, visual span is small, resulting in lower eye movement behavior.

Second, our research also found that color richness contributes positively (0.067) to the participants' visual-behavior evaluation; that is, the change of color significantly affects the participants' visual behavior in the scene (Figure 7). This result also confirms the findings of Huang and Lin [65]: higher hue and chromaticity changes can promote visual changes. 
Therefore, in future landscape design, we still need to pay attention to the sense of color change in the scene.

In addition, from the spatial characteristics, we also found that even spaces formed with the same elements have different factors affecting the visual behavior of participants because of their spatial characteristic differences (Table 5). For example, in this study, forest water landscape space has the same elements, but the spatial factor that significantly affects the participants' visual behavior in the space of dynamic water is mainly the spatial hierarchy of sense, while in the space of static water, it is the three-dimensional. That is, the spatial characteristics itself affect the participants' visual behavior, and this phenomenon presents the same trend as the research of Huang and Lin [65].

Furthermore, our research found that the presence or absence of a professional background affects the participants' visual attention to the forest recreation landscape space on a psychological level. Participants with landscape backgrounds paid more attention to low-openness, simple, but colorful spaces. However, the group without landscape background paid more attention to the regularity, three-dimensionality and abundant plant species in the space. We speculate that the reason for this result is that students majoring in landscape have received corresponding education and pay more attention to the color and composition of space, while students without majors in landscape pay more attention to the artificial attribute element, such as regularity and three-dimensionality of space. We call this phenomenon the "professional effect". Meanwhile, studies by Dupont and Brabyn also found that whether professional background affects people's visual behavior on landscape space, which also validates our research conclusion from the level of participants' psychological cognition; the same landscape may indeed cause different perceptions of different people $[39,40]$.

\subsection{Factors That Affect the Satisfaction Preference When Viewing the Scene}

First, the color richness (0.111) and color brightness (0.107) in the scene contribute positively to participants' satisfaction preferences. In other words, the participants prefer landscapes and colorful forest recreation landscape spaces. This is consistent with the research results of Huang and Lin [65]. High color changes are significantly positively correlated with satisfaction preference; that is, participants prefer landscapes with higher color changes.

Second, Deng et al. [66] pointed out in their study of urban green space that landscapes with higher diversity and complexity have higher aesthetic value. Although our research object is forest recreation landscape space, our research also confirmed this conclusion; the participants preferred forest recreation landscape space with rich landscape content and a strong sense of hierarchy (Figure 7).

That is, it is not a certain element that attracts people's attention in the space of forest recreation landscape, but the combination of certain landscape elements and the sense of space created by them. That is, whether it is in the urban green space or in the forest landscape, the participants all prefer scenes with rich landscapes and strong spatial hierarchy. In future landscape construction, we should pay more attention to the combination of landscape elements and their hierarchy.

Furthermore, in our research, we also found that the presence or absence of background did not affect participants' spatial cognitive evaluation of their preference for landscape space satisfaction. However, their degree of spatial cognitive indicators of preference for scene satisfaction is different. This is a very interesting phenomenon that shows that although the landscape space was the same, the constituent elements of the space bring different meanings to people on the level of psychological cognition. This means that for designers, in addition to considering the meaning of the element itself, we should also consider the deeper impact of the meaning of the landscape space on the acceptance and scope of different audiences. As research of Karahalil et al. pointed out, during the planning process we should integrate the information of participants' characteristics, moti- 
vations, demands and expectations, as well as tourist attitudes, preferences and perceived information, to guide the management decision of the natural park [67-70].

\subsection{Rationality and Limitations}

A: Rationality and feasibility

Our study, through the experiments of eye tracking and cognitive questionnaires, clarifies the factors that affect people's visual behavior and satisfaction preferences when viewing forest recreation landscape spaces. This is not only the focus of this study but also the depth of previous studies.

First, from the whole design of our experiment, using the technology of eye tracking to landscape assessment and other related fields has seen initial success $[25,31,46,51,54,58,65]$. In addition, a study by Amati et al. pointed out that it is feasible to apply the technology of eye tracking to the field of landscape research $[46,47,49,71,72]$.

Second, from the data of eye movement and analysis results, the photo sample acquisition and experiment procedures are implemented after referring to the effective methods of previous research and making proper improvements [31,39,45-47]. Meanwhile, some results of this study are also supported by the results of previous research [5,40,45,46,62-65].

Therefore, the experiments in our study are repeatable.

B: Limitations

First, the group of investigation in our study mainly selects masters and undergraduates of various majors from agricultural universities. However, in some related studies, some scholars have shown that the data of students were representative [32,52]. However, the participant's gender, age and other attributes will still impact their cognitive preference for forests [42]. Therefore, in-depth exploration of the factors that impact the visual behavior and satisfaction preferences of people of different genders and different age groups is also an important research topic for us in the future. This will help forest managers and planners to improve the design of forest recreation landscape space in a targeted and strategic way.

Second, this research used photo projection to collect the data of participant's visual behavior (fixation duration, etc.). Although related research has indicated that results of photobased eye tracking were consistent with those obtained in real scenes [31,36,37,39,40,45-47], other objective physical conditions, such as temperature, smell and negative oxygen ion concentration, in the forest recreation landscape space will also affect participant's visual behavior [34,35]. Therefore, further analysis of spatial perception factors that influence participant's visual behavior under the stimulation of real forest recreation landscape scenes and photos to provide better evidence for the spatial design of forest recreation landscapes is also worth further study.

Finally, from spatial types, we selected 6 representative forest recreation landscape spatial types as our experimental plots for relevant discussion. However, different landscape element characteristics (seasons, viewing distances, angle of view, etc.) will also impact people's visual behavior. Hence, further enrichment of the plots of the space of forest recreation landscape and exploring the relationship between satisfaction preference, landscape environment and visual behavior is also one of our important topics in the future.

\section{Conclusions and Suggestions}

\subsection{Conclusions}

As we mentioned earlier, most scholars in their studies have done more research on the eye movement patterns and characteristics of people in the landscape $[32,33,42,65]$.

However, the question of "what are the spatial cognition factors that affect participants" visual behavior and satisfaction preference in the space of forest recreation landscape?", "What is their contribution rate?", "Does the professional background will affect the people's visual behavior and satisfaction preferences?", and "Are there differences in spatial cognitive factors that affect participants' visual behaviors and satisfaction preferences at 
different types of forest recreation landscape spaces?" still to be further discussed. Particularly for forest recreation landscapes, through the technology of eye movement, exploring the spatial perception factors that affect visual behavior and satisfaction preferences is still in the early stage and needs to be studied and discussed in depth [34,35].

Based on the above, 6 spaces of typical forest recreation landscape in Liaoning Province, China, were taken as examples in our study, and using eye-tracking technology to discuss factors of spatial perception that impact people's visual behaviors and satisfaction preferences when appreciating the space of forest recreation landscape. We summarized the results as follows:

(1) Participants may not necessarily have higher visual-behavior evaluation in scenes with higher satisfaction preferences. The landscape space of the in-forest can attract the participants' visual attention, but their satisfaction preferences are relatively low.

In addition, after participants explore the forest waterscape space with higher satisfaction preference, they are more "interested" in local scene elements (buildings, etc.), so their attention is more inclined to focus on a few important landscape elements and local areas, and the degree of visual wandering is not high.

In the space of lookout, the participant's visual attention is scattered. We speculate that this result is related to the nature of the scene. In the space of lookout, participants are more inclined to look at the distant or surrounding landscape to relax themselves, so their visual behavior is more scattered and the degree of visual wandering is higher.

However, the space of the in-forest landscape, due to the scattered distribution of trees, participants inclined to searching for "interesting things" in a wide range when exploring the scene, so that they have higher visual attention, especially on the eye movement indicator of visual span.

(2) Overall, the spatial perception factors that affect the participants' visual behavior and satisfaction preferences are different in many indicators for the space of the forest recreation landscape. Among them, the two spatial perception indicators of landscape content richness and color richness in the scene jointly affect the participant's visual behavior and satisfaction preference. In addition, we found that the type of forest recreation landscape space also significantly affects the participants' visual behavior and satisfaction preferences.

(3) The presence or absence of professional background education affects the participant's visual-behavior evaluation of the recreation landscape space and also affects the participant's focus on the landscape preference. Among them, students majoring in landscape pay more attention to the richness of colors in the landscape space, but the brightness of the colors in the space has a bigger impact on the satisfaction preferences of students who are not majoring in landscape.

When the forest landscape type changes, the spatial perception factors that affect the participants' visual behavior and satisfaction preferences also change. Meanwhile, we found that even when the elements in different types of recreation landscape spaces are similar, factors that impact people's behavior characteristics of eye-movement and evaluation of overall cognitive also present differences. But on the whole, it is mainly landscape changes and spatial perception elements at the landscape level that affect participant's visual behavior in different types of forest recreation landscape space, and what affects participant's satisfaction preference also has the spatial perception factors of color in the scene.

\subsection{Suggestions}

First, for the improvement, transformation and construction of forest recreation landscape space quality, we should improve the spatial perception indicators in the scene according to the characteristics of the space itself, to improve the satisfaction preferences for the scene in a targeted manner, and try to allow participants to produce effective and positive visual behavior in the landscape space. 
(1) In forest waterscape space, the participants' satisfaction preferences are high and their visual behavior is highly concentrated on the lower center of the scene, the architecture of the scene or the combination of interesting elements (flowing water and the combination of stone landscape). The degree of sight wandering of visual attention is low, resulting in a lower evaluation of visual behavior (Figure 6).

Therefore, in the waterscape, we should improve the participants' satisfaction with the scene by improving the spatial perception indicators in the scene, allowing the participants' visual behavior to focus on the subject or interesting elements in the scene, and reducing unnecessary visual behavior as much as possible.

That is, in the space of dynamic water, we can reduce the sense of hierarchy in the scene and improve the color brightness, transparency and color richness in the scene; in static water space, we can reduce the three-dimensional sense of the scene and improve the landscape content richness and the neatness of space in the scene to improve the satisfaction preference of the scene and reduce the negative visual behavior.

(2) In the space of lookout, the participants' satisfaction preference is second only to the water landscape, and the visual behavior is more scattered; the visual wandering degree is greater (Figure 6), which is a better viewing place, allowing the participants to get a better visual view. Therefore, in the space of lookout, we should improve the scene's satisfaction preference by improving the spatial perception indicators of the scene and allowing participants to produce more positive visual behavior, so as to obtain a better landscape view.

That is, we can improve the neatness, transparency, layering, color brightness, and richness of landscape content, and reduce the richness of plants in the scene to improve participants' satisfaction with the scene and generate more frequent visual attention.

(3) In the space of in-forest landscape, the participant's satisfaction preference is inferior to lookout space, and the visual behavior is more scattered, but mainly focusing on the lower center of space or unique landscape elements (such as natural rocks, roots of trees, etc.), see Figure 6.

Therefore, in the space of broadleaf forest landscape, we can improve the openness, layering, color richness and regularity of the scene; in the space of coniferous forest landscape, we can improve richness, regularity and color brightness; in the space of mixed forest landscape, we can improve the transparency, landscape content richness, and regularity of the scene, so as to improve the participant's satisfaction, produce more concentrated visual attention, and reduce the degree of wandering of visual behavior.

Finally, for forest and existing forest parks, we should provide optimal recreational routes to different tourists on the park's tour route map according to the characteristics of the forest recreation landscape space to improve people's understanding of forest parks under different professional backgrounds and the visual behavior and satisfaction preferences of related recreation landscape space.

Author Contributions: Conceptualization, T.Z. and Y.G.; methodology, Z.Z., T.Z. and Y.G.; software, Y.G., S.Z.; validation, Y.G. and T.Z.; formal analysis, Y.G.; investigation, Z.Z., T.Z. and Y.G.; resources, T.Z.; data curation, T.Z. and Y.G.; writing-original draft preparation, Z.Z. and Y.G.; writing-review and editing, Z.Z., T.Z. and Y.G.; visualization, Y.G.; supervision, Z.Z., W.Z. and H.M.; project administration and funding acquisition, T.Z. All authors have read and agreed to the published version of the manuscript.

Funding: The research was supported by the Natural Science Foundation of China (31971714).

Data Availability Statement: The data presented in this study are available on request from the corresponding author. The data are not publicly available due to the copyright of relevant data in the article belonging to the research group rather than to individuals.

Acknowledgments: We would like to thank the participants in the experiment.

Conflicts of Interest: The authors declare no conflict of interest. 


\section{References}

1. Lan, S.R. Forest Park Is an Important Part of Urban Forest System. China Economic Net 2011. Available online: http://www.chla. com.cn/htm/2011/0629/89573.html (accessed on 29 June 2011).

2. Wei, H.; Hauer, R.J.; Guo, S. Daytime dynamic of spontaneous expressions of pedestrians in an urban forest park. Urban For. Urban Green. 2021, 65, 127326. [CrossRef]

3. Wei, H.; Ma, B.; Hauer, R.J.; Liu, C.; Chen, X.; He, X. Relationship between environmental factors and facial expressions of visitors during the urban forest experience. Urban For. Urban Green. 2020, 53, 126699. [CrossRef]

4. Liao, Q. Value of recreation space to the people-Multidisciplinary consideration on the harmonious development of society. J. Stud. Dialectics Nat. 2006, 3, 102-104.

5. Deng, S.; Yan, J.; Guan, Q.; Katoh, M. Short-term effects of thinning intensity on scenic beauty values of different stands. J. For. Res. 2013, 18, 209-219. [CrossRef]

6. Zhang, Z.; Qie, G.; Wang, C.; Jiang, S.; Li, X.; Li, M. Relationship between Forest Color Characteristics and Scenic Beauty: Case Study Analyzing Pictures of Mountainous Forests at Sloped Positions in Jiuzhai Valley, China. Forests 2017, 8, 63. [CrossRef]

7. Gao, Y.; Zhang, T.; Sasaki, K.; Uehara, M.; Jin, Y.; Qin, L. The spatial cognition of a forest landscape and its relationship with tourist viewing intention in different walking passage stages. Urban For. Urban Green. 2021, 58, 126975. [CrossRef]

8. Diener, E.; Suh, E. Measuring quality of life: Economic, social, and subjective indicators. Soc. Indic. Res. 1997, 40, 189-216. [CrossRef]

9. Dodge, R.; Daly, A.P.; Huyton, J.; Sanders, L.D. The challenge of defining wellbeing. Int. J. Wellbeing 2012, 2, 3. [CrossRef]

10. Li, Q.; Kobayashi, M.; Kumeda, S.; Ochiai, T.; Miura, T.; Kagawa, T.; Imai, M.; Wang, Z.; Otsuka, T.; Kawada, T. Effects of forest bathing on cardiovascular and metabolic parameters in middle-aged males. Evid. Based Complement. Altern. Med. 2016, 2016, 2587381. [CrossRef]

11. Janeczko, E.; Bielinis, E.; Wójcik, R.; Woźnicka, M.; Kędziora, W.; Łukowski, A.; Elsadek, M.; Szyc, K.; Janeczko, K. When Urban Environment Is Restorative: The Effect of Walking in Suburbs and Forests on Psychological and Physiological Relaxation of Young Polish Adults. Forests 2020, 11, 591. [CrossRef]

12. Horiuchi, M.; Endo, J.; Takayama, N.; Murase, K.; Nishiyama, N.; Saito, H.; Fujiwara, A. Impact of viewing vs. not viewing a real forest on physiological and psychological responses in the same setting. Int. J. Environ. Res. Public Health 2014, 11, 10883-10901. [CrossRef]

13. Song, C.; Ikei, H.; Miyazaki, Y. Physiological effects of visual stimulation with forest imagery. Int. J. Environ. Res. Public Health 2018, 15, 213. [CrossRef]

14. Song, C.; Ikei, H.; Miyazaki, Y. Effects of forest-derived visual, auditory, and combined stimuli. Urban For. Urban Green. 2021, 64, 127253. [CrossRef]

15. Park, B.J.; Tsunetsugu, Y.; Kasetani, T.; Kagawa, T.; Miyazaki, Y. The physiological effects of Shinrin-yoku (taking in the forest atmosphere or forest bathing): Evidence from field experiments in 24 forests across Japan. Environ. Health Prev. Med. 2010, 15, 18-26. [CrossRef]

16. Chiang, Y.C.; Li, D.; Jane, H.A. Wild or tended nature? The effects of landscape location and vegetation density on physiological and psychological responses. Landsc. Urban Plan. 2017, 167, 72-83. [CrossRef]

17. Van den Berg, A.E.; Jorgensen, A.; Wilson, E.R. Evaluating restoration in urban green spaces: Does setting type make a difference? Landsc. Urban Plan. 2014, 127, 173-181. [CrossRef]

18. Gatersleben, B.; Andrews, M. When walking in nature is not restorative-The role of prospect and refuge. Health Place 2013, 20, 91-101. [CrossRef]

19. Bielinis, E.; Janeczko, E.; Takayama, N.; Zawadzka, A.; Słupska, A.; Piętka, S.; Lipponen, M.; Bielinis, L. The effects of viewing a winter forest landscape with the ground and trees covered in snow on the psychological relaxation of young Finnish adults: A pilot study. PLoS ONE 2021, 16, e0244799. [CrossRef] [PubMed]

20. Janeczko, E.; Bielinis, E.; Tiarasari, U.; Woźnicka, M.; Kędziora, W.; Przygodzki, S.; Janeczko, K. How Dead Wood in the Forest Decreases Relaxation? The Effects of Viewing of Dead Wood in the Forest Environment on Psychological Responses of Young Adults. Forests 2021, 12, 871. [CrossRef]

21. Ulrich, R.S. Aesthetic and Affective Response to Natural Environment. In Behavior and the Natural Environment; Altman, I., Wohlwill, J.F., Eds.; Springer: Boston, MA, USA, 1983; pp. 85-125.

22. Liu, T. Research and Optimized Implementation of Eye Tracking Technology; Xidian University: Xian, China, 2011. (In Chinese)

23. Sara, B. E-Prime USER'S GUIDE; Psychology Software Tools, Inc.: Pittsburgh, PA, USA, 2002.

24. Yarbus, A.L. Eye Movements and Vision; Plenum Press: New York, NY, USA, 1967.

25. Dupont, L.; Antrop, M.; Van Eetvelde, V. Eye-tracking Analysis in Landscape Perception Research: Influence of Photograph Properties and Landscape Characteristics. Landsc. Res. 2013, 39, 417-432. [CrossRef]

26. Habron, D. Visual perceotlption of wild land in Scand. Landsc. Urban Plan. 1998, 42, 45-56. [CrossRef]

27. Rogge, E.; Dessein, J.; Gulinck, H. Stakeholders perception of attitudes towards major landscape changes held by the public: The case of greenhouse clusters in Flanders. Land Use Policy 2011, 28, 334-342. [CrossRef]

28. Duchowski, A.T. A breadth-first survey of eye-tracking applications. Behav. Res. Methods Instrum. Comput. 2002, 34, 455-470. [CrossRef] [PubMed] 
29. Zhang, Z.; Qie, G.F.; Wang, C.; Jiang, S.; Li, X.; Li, M. Application of eye-tracking assistive technology in forest landscape evaluation. J. World For. Res. 2017, 30, 19-23. (In Chinese)

30. Sevenant, M. Variation in Landscape Perception and Preference: Experiences from Case Studies in Rural and Urban Landscapes Observed by Different Groups of Respondents; Ghent University: Ghent, Belgium, 2010.

31. Dupont, L.; Ooms, K.; Antrop, M.; Van Eetvelde, V. Comparing saliency maps and eye-tracking focus maps: The potential use in visual impact assessment based on landscape photographs. Landsc. Urban Plan. 2016, 148, 17-26. [CrossRef]

32. Guo, S.; Zhao, N.; Zhang, J.; Xue, T.; Liu, P.; Xu, S.; Xu, D. Landscape visual quality assessment based on eye movement: College student eye-tracking experiments on tourism landscape pictures. Resour. Sci. 2017, 39, 1137-1147. (In Chinese)

33. Gao, Y.; Zhang, T.; Zhang, W.; Meng, H.; Zhang, Z. Research on visual behavior characteristics and cognitive evaluation of different types of forest landscape spaces. Urban For. Urban Green. 2020, 54, 126788. [CrossRef]

34. Liu, Y.; Hu, M.; Zhao, B. Interactions between elements and eye movement behavior under audio-visual integrated conditions. J. For. Res. 2020, 25, 21-30. [CrossRef]

35. Liu, Y.; Hu, M.; Zhao, B. Audio-visual interactive evaluation of the based on eye tracking experiments. Urban For. Urban Green. 2019, 46, 126476. [CrossRef]

36. Bell, S. Landscape pattern, perception and visualisation in the visual management of forests. Landsc. Urban Plan. 2001, 54, 201-211. [CrossRef]

37. Godschalk, D.R.; Paterson, R.G. Collaborative conflflict management comes of age. J. Archit. Plan. Res. 1999, 16, 91-95.

38. De Lucio, J.; Mohamadian, M.; Ruiz, J.; Banayas, J.; Bernaldez, F. Visual landscape exploration as revealed by eye movement tracking. Landsc. Urban Plan. 1996, 34, 135-142. [CrossRef]

39. Dupont, L.; Antrop, M.; Van Eetvelde, V. Does landscape related expertise influence the visual perception of landscape photographs? Implications for participatory landscape planning and management. Landsc. Urban Plan. 2015, 141, 68-77. [CrossRef]

40. Brabyn, L. Landscape classifification using GIS and national digital databases. Landsc. Res. 1996, 21, 277-299. [CrossRef]

41. Lange, E. Issues and Questions for Research in Communicating with Public through Visualizations. In Proceedings at Anhalt University of Applied Sciences Trends in Real-Time Landscape Visualization and Participation; Buhmann, E., Paar, P., Bishop, I., Lange, E., Eds.; Wichmann Verlag: Heidelberg, Germany, 2005; pp. 16-26.

42. Zhang, T.; Zhang, W.; Meng, H.; Zhang, Z. Analyzing Visitors' Preferences and Evaluation of Satisfaction Based on Different Attributes, with Forest Trails in the Akasawa National Recreational Forest, Central Japan. Forests 2019, 10, 431. [CrossRef]

43. Li, J. Forest Park Recreation Space Planning Research-Take Daping Forest Park in Dangtu County as an Example; Anhui Agricultural University: Anhui, China, 2017. (In Chinese)

44. Gu, Q.Y. Research on the Waterscape in Western Classical Gardens; Northeast Forestry University: Harbin, China, 2020. (In Chinese)

45. Cottet, M.; Vaudor, L.; Tronchère, H.; Roux-Michollet, D.; Augendre, M.; Brault, V. Using gaze behavior to gain insights into the impacts of naturalness on city dwellers' perceptions and valuation of a landscape. J. Environ. Psychol. 2018, 60, 9-20. [CrossRef]

46. Dupont, L.; Ooms, K.; Antrop, M.; Van Eetvelde, V. Testing the validity of a saliency-based method for visual assessment of constructions in the landscape. Landsc. Urban Plan. 2017, 167, 325-338. [CrossRef]

47. Dupont, L.; Ooms, K.; Duchowski, A.T.; Antrop, M.; Van Eetvelde, V. Investigating the visual exploration of the rural-urban gradient using eye-tracking. Spat. Cogn. Comput. 2017, 17, 65-88. [CrossRef]

48. Luo, M.C.; Yan, Y.J.; Tong, X.D. Preliminary Study on the Trail Model of the Forest Park; Hunan Forestry Science \& Technology: Changsha, China, 2003; Volume 1, pp. 27, 28, 31.

49. Wang, M. Research on the Eye Analysis Techniques Used in the Visual Quality Evaluation of Landscape: A Case Study of the Landscape of Danxia Landform, Sunan, Gansu. Master's Thesis, Nanjing University, Nanjing, China, 2011. (In Chinese).

50. Nordh, H.; Hagerhall, C.M.; Holmqvist, K. Tracking Restorative Components: Patterns in Eye Movements as a Consequence of a Restorative Rating Task. Landsc. Res. 2013, 38, 101-116. [CrossRef]

51. Sun, L.; Shao, H.; Li, S.; Huang, X.; Yang, W. Integrated application of eye movement analysis and beauty estimation in the visual landscape quality estimation of urban waterfront park. Int. J. Pattern Recognit. Artif. Intell. 2018, 32, 19. [CrossRef]

52. Van Den Berg, A.E.; Joye, Y.; Koole, S.L. Why viewing nature is more fascinating and restorative than viewing buildings: A closer look at perceived complexity. Urban For. Urban Green. 2016, 20, 397-401. [CrossRef]

53. Daniel, T.C. Whither scenic beauty? Visual landscape quality assessment in the 21st century. Landsc. Urban Plan. 2001, 54, 267-281. [CrossRef]

54. Hands, D.E.; Brown, R. Enhancing visual preference of ecological rehabilitation sites. Landsc. Urban Plan. 2002, 58, 57-70. [CrossRef]

55. Zhang, W.D.; Liang, Q.; Fang, H.L.; Zhang, Q.F. An eye-movement research on city greening landscape appreciation. Psychol. Sci. 2009, 32, 801-803. (In Chinese)

56. Berto, R.; Massaccesi, S.; Pasini, M. Do eye movements measured across high and low fascination photographs differ? Addressing Kaplan's fascination hypothesis. J. Environ. Psychol. 2008, 28, 185-191. [CrossRef]

57. Olivia, A.; Mack, M.L.; Shrestha, M.; Peeper, A. Identifying the perceptual dimensions of visual complexity of scenes. Cogn. Sci. Soc. 2004, 26, 1041-1046.

58. Shao, H. Landscape Quality Evaluation of Coal Mining Collapsed Land Based on Eye Movement Analysis: A Case Study of Xuzhou City; China University of Mining and Technology: Jiangsu, China, 2008. (In Chinese) 
59. Sui, X.; Gao, M.; Xiang, H.W. Eye Movement Theory and Empirical Research in Visual Cognition; Science Press: Beijing, China, 2018. (In Chinese)

60. Kaplan, S.; Kaplan, R. The visual environment: Public participation in design and planning. J. Soc. Issues 1989, 45, 59-86. [CrossRef]

61. Kaplan, R.; Kaplan, S. The Experience of Nature: A Psychological Perspective; Cambridge University Press: New York, NY, USA, 1989.

62. Wang, Y.; Sparks, B.A. An Eye-Tracking Study of Tourism Photo Stimuli: Image Characteristics and Ethnicity. J. Travel Res. 2014, 55, 588-602. [CrossRef]

63. Stamps, A.E. Entropy, visual diversity, and preference. J. Gen. Psychol. 2002, 129, 300-320. [CrossRef]

64. Khachatryan, H.; Rihn, A.; Hansen, G.; Clem, T. Landscape aesthetics and maintenance perceptions: Assessing the relationship between homeowners' visual attention and landscape care knowledge. Land Use Policy 2020, 95, 104645. [CrossRef]

65. Huang, A.S.-H.; Lin, Y.-J. The effect of landscape colour, complexity and preference on viewing behaviour. Landsc. Res. 2019, 45, 214-227. [CrossRef]

66. Deng, L.; Luo, H.; Ma, J.; Huang, Z.; Sun, L.-X.; Jiang, M.-Y.; Zhu, C.-Y.; Li, X. Effects of integration between visual stimuli and auditory stimuli on restorative potential and aesthetic preference in urban green spaces. Urban For. Urban Green. 2020, 53, 126702. [CrossRef]

67. Karahalil, U.; Başkent, E.Z.; Köse, S. Integrating visitor characteristics and preferences into forest management plans in protected areas: A case study in Köprülü Canyon National Park. J. Prot. Mt. Areas Res. 2015, 7, 5-17. [CrossRef]

68. Eagles, P.F.J.; McCool, S.F. Tourism in Parks and Protected Areas: Planning and Management; CABI Publishing: Wallingford, UK, 2002; p. 330.

69. Manning, R.E. Studies in Outdoor Recreation: Search and Research for Satisfaction; Oregon State University Press: Corvallis, OR, USA, 2011. [CrossRef]

70. Obua, J.; Harding, D. Visitor characteristics and attitudes towards Kibale National Park, Uganda. Tour. Manag. 1996, 17, 495-505. [CrossRef]

71. Amati, M.; Parmehr, E.G.; McCarthy, C.; Sita, J. How eye-catching are natural features when walking through a park? Eye-tracking responses to videos of walks. Urban For. Urban Green. 2018, 31, 67-78. [CrossRef]

72. Zeng, X.Y. A Dissertation Submitted in Partial Fulfillment of the Requirements for the Degree of Master of Landscape Architecture; Huazhong University of Science and Technology: Wuhan, China, 2017. (In Chinese) 